\title{
DYNAMIC RESPONSE ANALYSES AND MODEL VIBRATION TESTS ON SEISMIC ISOLATING FOUNDATION OF BRIDGE PIER
}

\author{
Tongxiang $\mathrm{AN}^{1}$ and Osamu KIYOMIYA ${ }^{2}$ \\ ${ }^{1}$ Member of JSCE, Research Associate of Advanced Res. Inst. for Sc. and Eng., Waseda University \\ (Okubo 3-4-1, Shinjuku-ku, Tokyo 169-8555, Japan) \\ E-mail: antongxiang@ybb.ne.jp \\ ${ }^{2}$ Fellow of JSCE, Professor, Dept. of Civil Eng., Waseda University \\ (Okubo 3-4-1, Shinjuku-ku, Tokyo 169-8555, Japan) \\ E-mail: k9036@waseda.jp
}

\begin{abstract}
In this study, the oscillation behavior and the aseismicity of bridge piers with isolating foundations are investigated. An isolating foundation is formed by installing isolation materials such as sand, gravel and PTFE (Teflon sheet) between the footing and the pier foundation and mainly utilizes the relative displacements (sliding and rocking) between the footing and the foundation to absorb and dissipate energy during large-scale earthquakes. The governing equations of motion are derived and dynamic response analyses and model vibration tests on a single pier are carried out. The results show that this isolating system has a significant positive effect in decreasing responses during earthquakes.
\end{abstract}

Key Words: bridge pier, dynamic response analysis, model vibration test, seismic isolating foundation, sliding, rocking, lift-off

\section{INTRODUCTION}

The Hyogo-ken Nanbu Earthquake happened on 17th January, 1995, caused destructive damage to many structures, including bridges. In light of this crisis, the demand for bridge structures possessing stronger earthquake resistance has been increasing. In order to meet this demand, a concept for stronger earthquake-resistant design that adopts an isolating system in place of the conventional design code is being considered. Currently, an isolating system based on equipment consisting of laminated rubber bearings is normally used in bridge engineering. However, this isolating system is unsuitable for bridges on soft ground ${ }^{1}$. Recently, it has become known that a half-fixed combination made into hinge joints, pistol joints, etc. at pile heads is being studied as an isolating system; however, these isolating devices have limited deformation capability and might not accommodate the large deformation of a foundation built on soft ground.

One of the promising schemes to protect structures against earthquake damage is foundation isolation.
An isolating system installed between the footing and the pier foundation may reduce the transmission of earthquake energy from the ambient ground by making use of relative displacement (sliding and rocking). In the case of spread foundations for bridges, the rocking motion associated with earthquakes causes the edges of the footings to separate from the ground (lift-off), thereby resulting in a decrease in earthquake energy ${ }^{2)}$. A tall, slender structure is more stable in an earthquake due to its ability to rock in accordance with the earthquake motion ${ }^{3)}$. Furthermore, it is known that the cable-stayed Rion-Antirion Bridge in Greece uses gravel placed between the main tower and the steel pipe pile-reinforced foundation to reduce earthquake load by allowing rocking and sliding at the base of the main tower ${ }^{4}$. A number of Japanese engineers have tried to adopt a foundation isolating system for bridge piers in the past ${ }^{5)}$. They paid attention to the hysteretic damping of the isolating materials, such as high damping rubber, in order to achieve an aseismatic effect based on the high damping material. Of these cases, the authors have adopted an isolating 


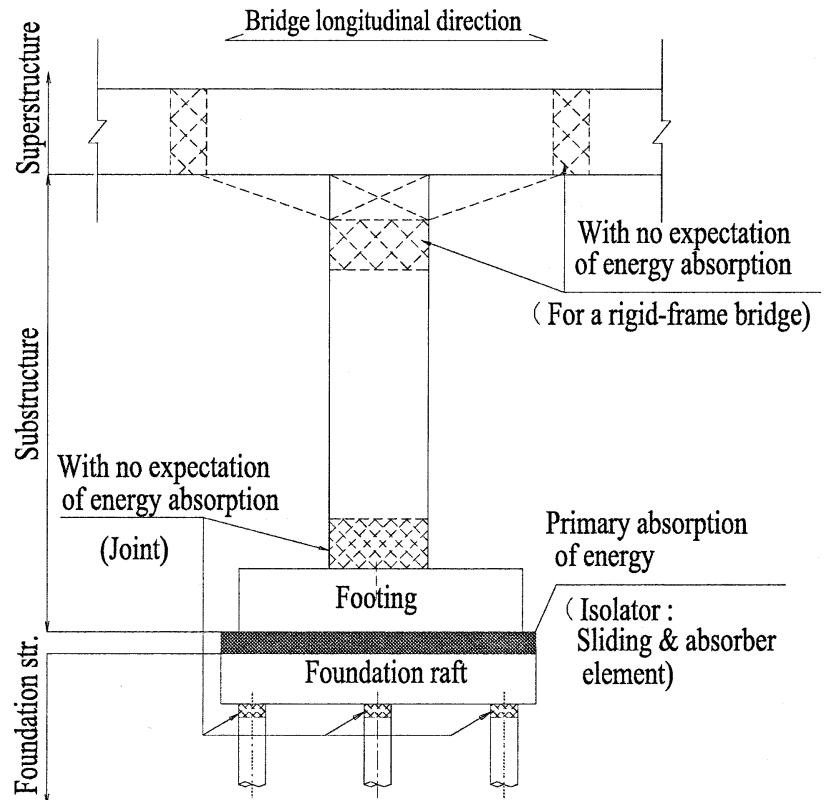

Fig. 1 A bridge pier with the isolation foundation

system for ordinary type piers, based mainly on the use of relative displacement to absorb and dissipate earthquake energy. As for the isolating materials, the authors selected sand, gravel or PTFE, which are relatively inexpensive and enable easy control of both friction and rigidity. Fig. 1 shows a bridge pier with an isolating system in which the isolator is located between the footing and the foundation. The earthquake energy is absorbed by the isolating system; hence there is no expectation of energy absorption by either the ends of the columns, the heads of the piles (for a pile foundation), or the joints of the superstructure and pier columns (for a rigid-frame bridge). A pile foundation is shown in Fig. 1. This isolating system can also be applied to gravity-type foundations. In the design concept of a bridge with this isolating system, no sliding is allowed at the isolator except in cases of level 2 earthquake ground motion as provided in Specifications for Highway Bridges (Part V Seismic Design). Such a concept is achievable by selecting appropriate isolating materials or setting-up a stopper or a shear key. Furthermore, it is thought that this isolating system may decrease adverse effects caused by large ground movement in cases where a bridge is constructed across an active fault, especially a strike-slip type fault, or near a revetment where large lateral movement is predicted by liquefaction of loose sand.

The vibration behavior of the portion above the isolator may be described in terms of the six modes of plane motion: rest, slide, rock, slide-rock, translation jump and rocking jump ${ }^{6}$. Beginning with Kimura and Iida's study on rocking in rectangular columns ${ }^{7}$, there have been many studies investigating the vibration behavior of free-standing rigid bodies ${ }^{8)-10)}$.

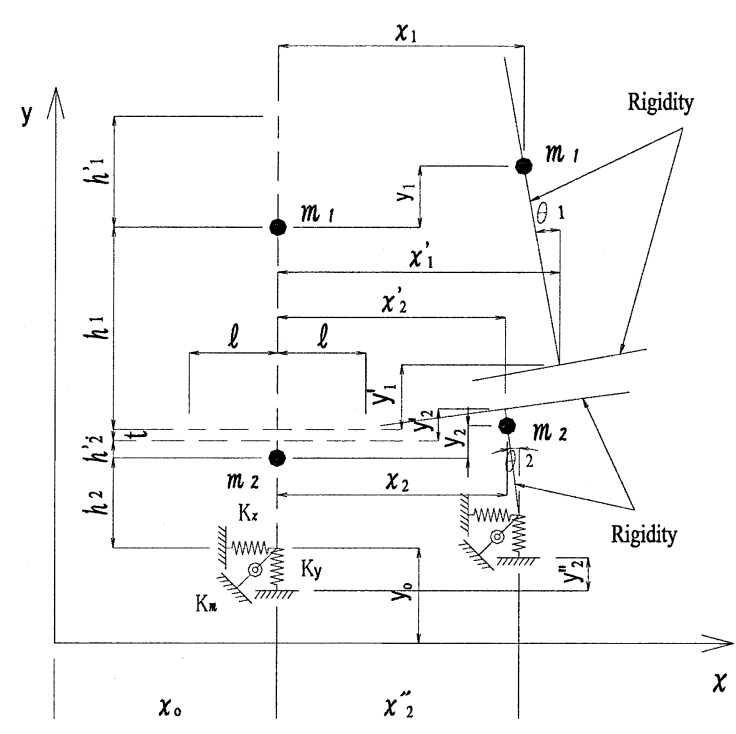

Fig. 2 Coordinate system for the oscillation system of a bridge pier with the isolation foundation

However, past research has assumed models consisting of rigid bodies on rigid foundations. The interface between two rigid objects demonstrates rigid-plastic property and the rotation axis is located at either edge of the rigid body. Furthermore, almost all studies are limited in their mathematical and numerical analysis. In this study, the isolating system made of sliding or shock absorbing material demonstrates elastic-plastic property, and rocking occurs when the edge of the footing separates from the isolating system. This separation is called lift-off. This paper will firstly derive the governing equations of the motion of a pier with this isolation system, and then describe the dynamic response analyses and model vibration tests.

\section{EQUATIONS OF MOTION}

\section{(1) Equations of motion}

A bridge pier with the isolation system shown in Fig. 1 can be modeled into a two-mass $\left(m_{1}, m_{2}\right)$ oscillation system as shown in Fig. 2. Here, $m_{1}$ is the mass of the portion above the isolator, i.e. the mass of the substructure and the superstructure portion that is supported by the substructure concerned. Yielding of pier columns with a seismic isolation foundation is not permitted here, and substructure deformation for a not high reinforced concrete pier is too small to be considered relevant for the modeling. Therefore the portion above the isolator is modeled into a single mass. $m_{2}$ is the mass of the portion below the isolator, i.e. the mass of the foundation structure. The height of the gravity center of the portion above the isolator is denoted $h_{1}$, and the height of the gravity center of the portion below the isolator is denoted $h_{2}$. 


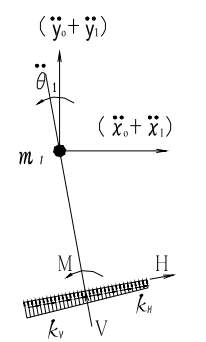

(1) Above islator : No lift-off

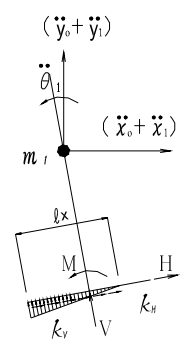

(2) Above islator : Lift-off

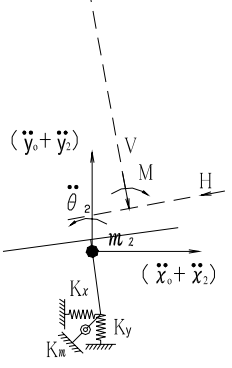

(3) Foundation structure

Fig. 3 Acceleration and interfaceforce

The foundation structure and soil resistance are modeled into horizontal spring $K_{x}$, vertical spring $K_{y}$, and rotational spring $K_{m}$. The springs are located where the coupling of the horizontal and rotational springs becomes zero, and $K_{x}, K_{m}$ are adjusted by the spring location.

When the deformations of the foundation and the isolator are considered alone, ground movements with accelerations $\ddot{x}_{o}(t), \ddot{y}_{o}(t)$ are considered in the horizontal and vertical directions, respectively; providing no jump occurs and applying Newton's Second Law, the governing equations of motion may be expressed as follows.

Concerning $m_{1}$ above the isolator, the following equations are derived:

$$
\begin{gathered}
m_{1}\left(\ddot{x}_{1}+\ddot{x}_{0}\right)+c_{1 x}\left(\dot{x}_{1}^{\prime}-\dot{x}_{2}^{\prime}\right) \\
-H \cos \theta_{1}+V \sin \theta_{1}=0 \\
m_{1}\left(\ddot{y}_{1}+\ddot{y}_{0}-g\right)+c_{1 y}\left(\dot{y}_{1}^{\prime}-\dot{y}_{2}^{\prime}\right) \\
-H \sin \theta_{1}-V \cos \theta_{1}=0 \\
J_{1} \ddot{\theta}_{1}+c_{1 \theta}\left(\dot{\theta}_{1}-\dot{\theta}_{2}\right)-H h_{1}-M=0
\end{gathered}
$$

Concerning $m_{2}$ below the isolator, the following equations are also derived:

$$
\begin{aligned}
m_{2}\left(\ddot{x}_{2}+\ddot{x}_{0}\right)+c_{2 x} \dot{x}_{2}^{\prime \prime}-c_{1 x}\left(\dot{x}_{1}^{\prime}-\dot{x}_{2}^{\prime}\right) & \\
& +H \cos \theta_{1}-V \sin \theta_{1}+K_{x} x_{2}^{\prime \prime}=0 \\
m_{2}\left(\ddot{y}_{2}+\right. & \left.\ddot{y}_{0}-g\right)+c_{2 y} \dot{y}_{2}^{\prime \prime}-c_{1 y}\left(\dot{y}_{1}^{\prime}-\dot{y}_{2}^{\prime}\right) \\
& +H \sin \theta_{1}+V \cos \theta_{1}+K_{y} y_{2}^{\prime \prime}=0 \\
& J_{2} \ddot{\theta}_{2}+c_{2 \theta} \dot{\theta}_{2}-c_{1 \theta}\left(\dot{\theta}_{1}-\dot{\theta}_{2}\right)+M \\
+ & \left\{H \sin \theta_{1}+V \cos \theta_{1}-c_{1 y}\left(\dot{y}_{1}^{\prime}-\dot{y}_{2}^{\prime}\right)\right\} \\
& \cdot\left(x_{1}^{\prime}-x_{2}\right)-\left\{H \cos \theta_{1}-V \sin \theta_{1}\right.
\end{aligned}
$$




$$
\begin{gathered}
V=-k_{v} A_{e}\left\{-\left(x_{1}^{\prime}-x_{2}^{\prime}\right) \sin \theta_{1}+1 / 2\left[\left(y_{1}^{\prime}-y_{2}^{\prime}\right)\right.\right. \\
\left.\left.-A B S\left(\theta_{1}-\theta_{2}\right) \ell-\delta_{v o}\right] \cos \theta_{1}\right\} \\
M=-S\left(\theta_{1}-\theta_{2}\right) V\left(\ell-\ell_{x} / 3\right)
\end{gathered}
$$

When slip and lift-off occur simultaneously:

$$
\begin{gathered}
H=-S\left(\dot{x}_{1}^{\prime}-\dot{x}_{2}^{\prime}\right) \mu V-k_{H 2} A_{e}\left\{\left(x_{1}^{\prime}-x_{2}^{\prime}\right)\right. \\
\left.\cdot \cos \theta_{1}+\left(y_{1}^{\prime}-y_{2}^{\prime}\right) \sin \theta_{1}\right\} \\
V=-1 / 2 k_{v} A_{e}\left\{\left(y_{1}^{\prime}-y_{2}^{\prime}\right)-A B S\left(\theta_{1}-\theta_{2}\right) \ell\right. \\
\left.\quad-\delta_{v o}\right\} \cos \theta_{1} \\
M=-S\left(\theta_{1}-\theta_{2}\right) V\left(\ell-\ell_{x} / 3\right)
\end{gathered}
$$

where $A, I$ are the area and inertial moment of the footing base, respectively. $2 \ell$ is the width of the footing in the vibration direction. $S(a)$ is defined by the sign of a, if $a>0$, then $S(a)=1$, else $S(a)=-1 . \mu$ is the coefficient of the sliding friction. $k_{H 2}$ is the secondary spring constant after sliding of the isolator as shown in Fig. 4. $k_{H 2}$ is generally zero for the sliding system when restoring force is ignored. $\ell_{x}$, $A_{e}$ are the effective width and the area of the footing when lift-off occurs, respectively, which may be represented as follows:

$$
\begin{gathered}
A_{e}=2 B \ell_{x} \\
\ell_{x}=\left\{\left(y_{1}^{\prime}-y_{2}^{\prime}\right)-A B S\left(\theta_{1}-\theta_{2}\right) \ell\right. \\
\left.-\delta_{v o}\right\} / \sin \left(\theta_{1}-\theta_{2}\right)
\end{gathered}
$$

where $B$ is the width of the footing in vibration transversal direction and $\delta_{v o}$ is the initial normal deformation of the isolator.

$$
\delta_{v o}=m_{1} g /\left(k_{v} A\right)
$$

\section{(2) Occurrence conditions for each motion mode}

According to whether or not the interface forces exceed the critical points represented in equation (11), the motion mode may be distinguished.

$$
\left.\begin{array}{l}
H_{o}=\mu V+k_{H_{2}} A \delta_{o} \\
M_{o}=\frac{V}{A} Z=\frac{\ell V}{3}
\end{array}\right\}
$$

Where $\delta_{o}$ is the yield displacement at the isolator of sliding represented in equation (12); and $Z$ is the section modulus of footing bottom:

$$
\delta_{o}=\frac{\mu V}{A\left(k_{H}-k_{H 2}\right)}
$$

If the interface force $H$ does not exceed the resistance produced by the friction force and no tensile stress occurs at the base of the footing, i.e. $H<H_{o}$ and $M<M_{o}$, sliding and lift-off do not occur.

Where the interface force $H$ exceeds the resistance produced by the friction but no tensile stress occurs

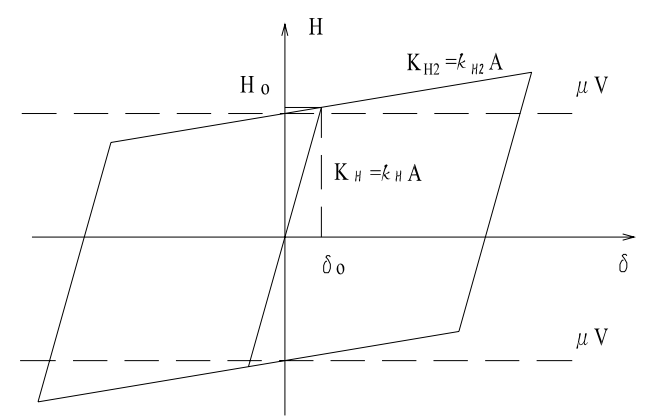

Fig. $4 H \sim \delta$ Hysteretic curve

at the base of the footing, i.e. $H=H_{o}$ but $\mathrm{M}<M_{o}$, sliding does occur. In this case, ignoring the angular acceleration $\ddot{\theta}_{1}$ and the damping $c_{1 \theta}$ and assuming the secondary spring constant of the isolator $k_{H 2}$ is small, the occurrence condition for sliding alone may be expressed by the following equation:

$$
\left.\begin{array}{l}
A B S(H)=H_{o}=\mu V \\
\mu \leq \ell / 3 h_{1}
\end{array}\right\}
$$

In addition, if $\theta_{1}$ is small enough and assuming $V$ $=m_{1} g$ when $\left(\ddot{y}_{1}+\ddot{y}_{0}\right)$ and $c_{1 y}$ are small, reference equation (1a), the first equation of equation (13), may be combined into the following equation:

$$
\mu=\left(\ddot{x}_{1}+\ddot{x}_{0}\right) / g
$$

Because it is impossible that tensile stress is resisted between the footing and the isolator, where the normal reaction stress located either edge at the base of the footing becoming tensile; but, $H$ does not exceed the resistance produced by the friction force, i.e. $H<H_{o}$ but $M=M_{o}$, lift-off may occur.

If not only the interface force $H$ exceeds the resistance produced by the friction force but also tensile stress occurs at the base of the footing, i.e. $H=H_{o}$ and $M=M_{o}$, sliding and lift-off do occur.

\section{(3) Approximation of the motion equations}

If $\theta_{1}$ and $\theta_{2}$ are small, the following approximation may be introduced.

$$
\left.\begin{array}{l}
\sin \theta=\theta \\
\cos \theta=1
\end{array}\right\}
$$

Substitutions of the above equation into equations (1)-(2) provide the following equations.

$$
\begin{gathered}
m_{1} \ddot{x}_{1}+c_{1 x}\left(\dot{x}_{1}^{\prime}-\dot{x}_{2}^{\prime}\right)-H+V \theta_{1}=-m_{1} \ddot{x}_{0} \\
m_{1} \ddot{y}_{1}+c_{1 y}\left(\dot{y}_{1}^{\prime}-\dot{y}_{2}^{\prime}\right)-H \theta_{1}-V=-m_{1}\left(\ddot{y}_{o}-g\right) \\
J_{1} \ddot{\theta}_{1}+c_{1 \theta}\left(\dot{\theta}_{1}-\dot{\theta}_{2}\right)-H h_{1}-M=0 \\
m_{2} \ddot{x}_{2}+c_{2 x} \dot{x}_{2}^{\prime \prime}-c_{1 x}\left(\dot{x}_{1}^{\prime}-\dot{x}_{2}^{\prime}\right) \\
+H-V \theta_{1}+K_{x} x_{2}^{\prime \prime}=m_{2} \ddot{x}_{0} \\
m_{2} \ddot{y}_{2}+c_{2 y} \dot{y}_{2}^{\prime \prime}-c_{1 y}\left(\dot{y}_{1}^{\prime}-\dot{y}_{2}^{\prime}\right) \\
+H \theta_{1}+V+K_{y} y_{2}^{\prime \prime}=m_{2}\left(\ddot{y}_{0}-g\right)
\end{gathered}
$$




$$
\begin{gathered}
J_{2} \ddot{\theta}_{2}+c_{2 \theta} \dot{\theta}_{2}-c_{1 \theta}\left(\dot{\theta}_{1}-\dot{\theta}_{2}\right)+M \\
+\left\{H \theta_{1}+V-c_{1 y}\left(\dot{y}_{1}^{\prime}-\dot{y}_{2}^{\prime}\right)\right\}\left(x_{1}^{\prime}-x_{2}\right) \\
-\left\{H-V \theta_{1}-c_{1 x}\left(\dot{x}_{1}^{\prime}-\dot{x}_{2}^{\prime}\right)\right\}\left(y_{1}^{\prime}+t+h_{2}^{\prime}-y_{2}\right) \\
+K_{x} x_{2}^{\prime \prime} h_{2}+K_{y} y_{2}^{\prime \prime} h_{2} \theta_{2}+K_{m} \theta_{2}=0 \quad\left(2 \mathrm{c}^{\prime}\right)
\end{gathered}
$$

Substitutions of equation (14) into equations (4)-(7) provide the following equations:

$$
\begin{array}{cc}
H=-k_{H} A\left\{\left(x_{1}^{\prime}-x_{2}^{\prime}\right)+\left(y_{1}^{\prime}-y_{2}^{\prime}\right) \theta_{1}\right\} & \left(4 \mathrm{a}^{\prime}\right) \\
V=-k_{V} A\left\{-\left(x_{1}^{\prime}-x_{2}^{\prime}\right) \theta_{1}+\left(y_{1}^{\prime}-y_{2}^{\prime}\right)\right\} & \left(4 \mathrm{~b}^{\prime}\right) \\
M=-k_{V} I\left(\theta_{1}-\theta_{2}\right) & \left(4 \mathrm{c}^{\prime}\right) \\
H=-S\left(\dot{x}_{1}-\dot{x}_{2}\right) \mu V-k_{H 2} A\left\{\left(x_{1}^{\prime}-x_{2}^{\prime}\right)\right. & \left(5 \mathrm{a}^{\prime}\right) \\
\left.+\left(y_{1}^{\prime}-y_{2}^{\prime}\right) \theta_{1}\right\} & \left(5 \mathrm{~b}^{\prime}\right) \\
V=-k_{V} A\left(y_{1}^{\prime}-y_{2}^{\prime}\right) & \left(5 \mathrm{c}^{\prime}\right) \\
M=-k_{V} I\left(\theta_{1}-\theta_{2}\right) & \left(6 \mathrm{a}^{\prime}\right) \\
H=-k_{H} A_{e}\left\{\left(x_{1}^{\prime}-x_{2}^{\prime}\right)+\left(y_{1}^{\prime}-y_{2}^{\prime}\right) \theta_{1}\right\} & \left(6 \mathrm{~b}^{\prime}\right) \\
V=-k_{V} A_{e}\left\{-\left(x_{1}^{\prime}-x_{2}^{\prime}\right) \theta_{1}+1 / 2\left[\left(y_{1}^{\prime}-y_{2}^{\prime}\right)\right.\right. \\
\left.\left.-A B S\left(\theta_{1}-\theta_{2}\right) \ell-\delta_{v o}\right]\right\} \\
M=-S\left(\theta_{1}-\theta_{2}\right) V\left(\ell-\ell_{x} / 3\right) \\
H=-S\left(\dot{x}_{1}^{\prime}-\dot{x}_{2}^{\prime}\right) \mu V-k_{H 2} A_{e}\left\{\left(x_{1}^{\prime}-x_{2}^{\prime}\right)\right. \\
\left.\quad+\left(y_{1}^{\prime}-y_{2}^{\prime}\right) \theta_{1}\right\}
\end{array}
$$

$$
M=-S\left(\theta_{1}-\theta_{2}\right) V\left(\ell-\ell_{x} / 3\right)
$$

The governing equations have geometrical and material nonlinear properties. According to the above equations, the numerical analysis method can be adopted to simulate the oscillation of the isolating system.

\section{DYNAMIC RESPONSE ANALYSES}

\section{(1) Analysis outline}

In order to investigate the oscillation behavior and the aseismicity of this seismic isolating system, numerical simulation by time-history response analysis is carried out on a bridge pier with the isolating system on soft ground. The bridge pier used in the simulation is an ordinary type highway bridge pier: a T-type $\mathrm{RC}$ pier with a column in a rectangular $4.0 \mathrm{~m}$ (longitudinal) $\times 4.5 \mathrm{~m}$ (transversal) section and a pile foundation structure that consists of 12 cast-in-place piles. The column is $10.2 \mathrm{~m}$ of the total height of the pier which is $15.7 \mathrm{~m}$. The distance from the gravity center of the superstructure to the top of the pier is $2.3 \mathrm{~m}$. The diameter and length of the pile are $1.20 \mathrm{~m}$ and $40.0 \mathrm{~m}$ respectively. The surface ground on which the pier is located is over $43.0 \mathrm{~m}$ in depth and consists of loose sand and soft clay. The dynamic characteristic value of the surface ground is $0.92 \mathrm{~s}$,

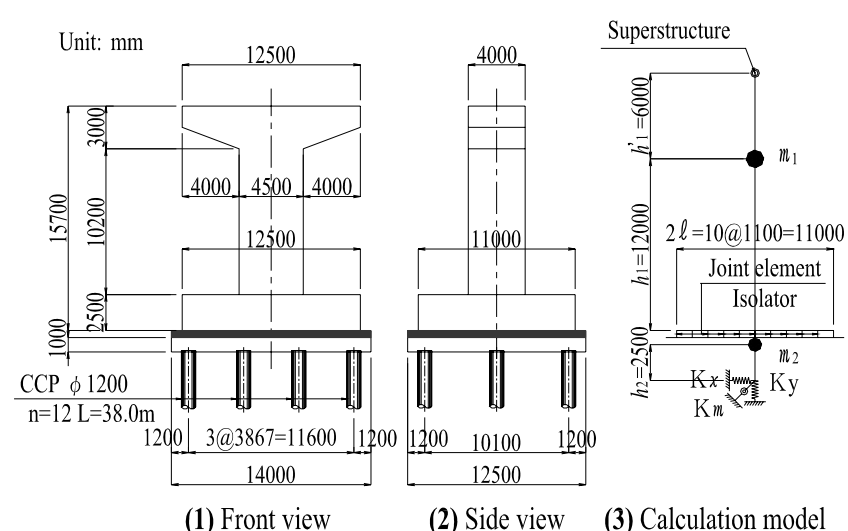

Fig. 5 Calculation bridge pier

Table 1 Mass and rotational inertia mass

\begin{tabular}{|c|c|c|c|}
\hline$m_{1}(\mathrm{~kg})$ & $m_{2}(\mathrm{~kg})$ & $J_{1}\left(\mathrm{kgm}^{2}\right)$ & $J_{2}\left(\mathrm{kgm}^{2}\right)$ \\
\hline $3.9 \times 10^{6}$ & $4.5 \times 10^{5}$ & $2.1 \times 10^{8}$ & $6.0 \times 10^{6}$ \\
\hline
\end{tabular}

Table 2 Height

\begin{tabular}{|r|r|r|r|}
\hline$h_{1}(\mathrm{~m})$ & $h_{2}(\mathrm{~m})$ & $h^{\prime}{ }_{1}(\mathrm{~m})$ & $h^{\prime}{ }_{2}(\mathrm{~m})$ \\
\hline 12.0 & 2.5 & 6.0 & 0.5 \\
\hline
\end{tabular}

Table 3 Constants of the base springs and damping ratio

\begin{tabular}{|c|r|r|r|}
\hline $\mathrm{K}_{\mathrm{x}}(\mathrm{kN} / \mathrm{m})$ & $\mathrm{K}_{\mathrm{y}}(\mathrm{kN} / \mathrm{m})$ & $\mathrm{K}_{\mathrm{m}}(\mathrm{kNm} / \mathrm{rad})$ & Damping ratio \\
\hline $5.0 \times 10^{6}$ & $7.5 \times 10^{6}$ & $1.0 \times 10^{8}$ & $10.0 \%$ \\
\hline
\end{tabular}

i.e. type III ground according to the seismic designs specified in Specifications for Highway Bridges (Part V Seismic Design). Moreover, the footing width in the vibration direction is $11.0 \mathrm{~m}$ in conformance with equation 15.

$$
2 \ell \geq 3 k_{h} \cdot h_{1}
$$

where $k_{h}=0.30$ is the level 1 lateral seismic coefficient specified in Specifications for Highway Bridges (Part V Seismic Design). The bridge pier with isolating system and the calculation model used in the simulation are shown in Fig. 5. The mass of the superstructure portion supported by the concerned pier is $2.26 \times 10^{6} \mathrm{~kg}$. The specified concrete strength of the column is $30 \mathrm{MPa}$. The main factors of the calculation model are presented in Table 1-3. The meaning of each symbol used is shown in Fig. 2.

According to equations (11)-(13), it is shown that the friction coefficient $\mu$, the ratio for $\ell / 3 h_{1}$, the critical displacement of sliding $\delta_{o}$ and the spring constant of the isolator affect the interface forces. To study the influence of each parameter on the oscillation behavior of the pier, the above parameters are adjusted in the simulations. In addition, to make an exact evaluation of the sliding and lift-off between the footing and the foundation raft, the isolator is modeled into ten joint spring elements in the vibration direction.

The dynamic responses are calculated by direct integration of the vibration equations in New Mark- $\beta$ 

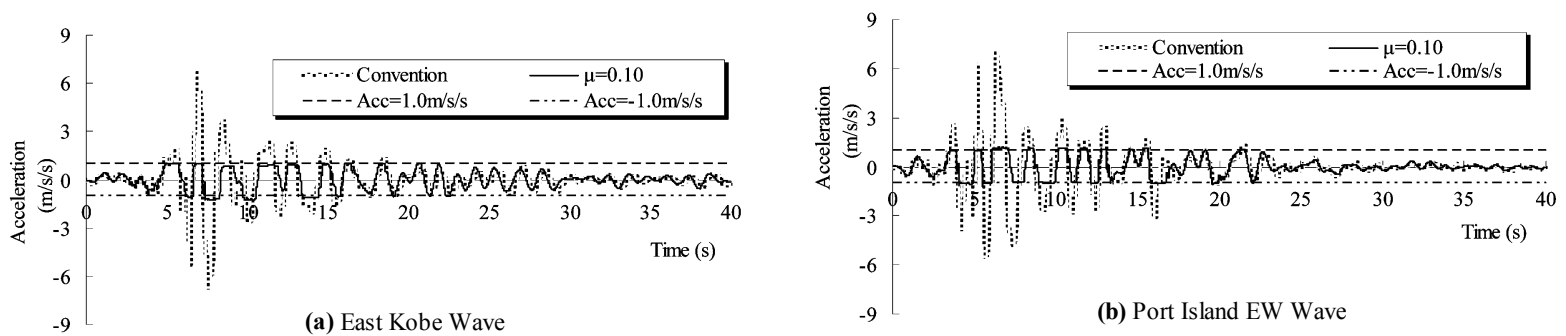

(1) Horizontal acceleration ( $\mu=0.10$ : Gravity center above the isolator; Convention: Superstructure)
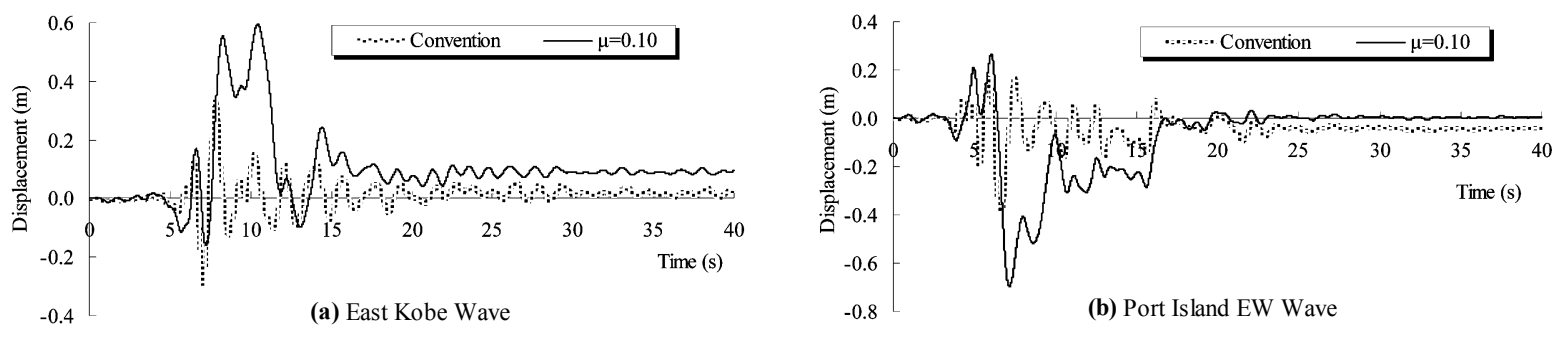

(2) Horizontal displacement ( $\mu=0.10$ : Gravity center above the isolator; Convention: Superstructure)
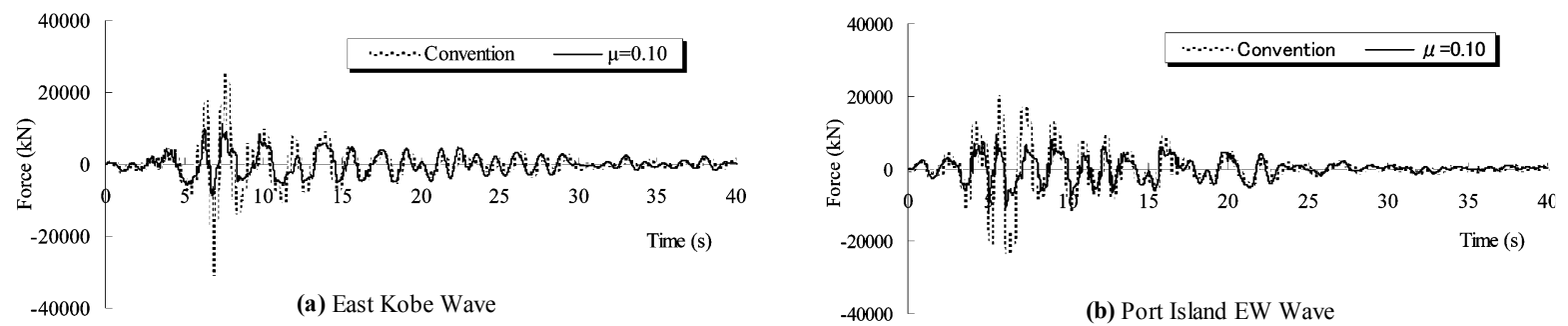

(3) Horizontal reaction force of the base spring
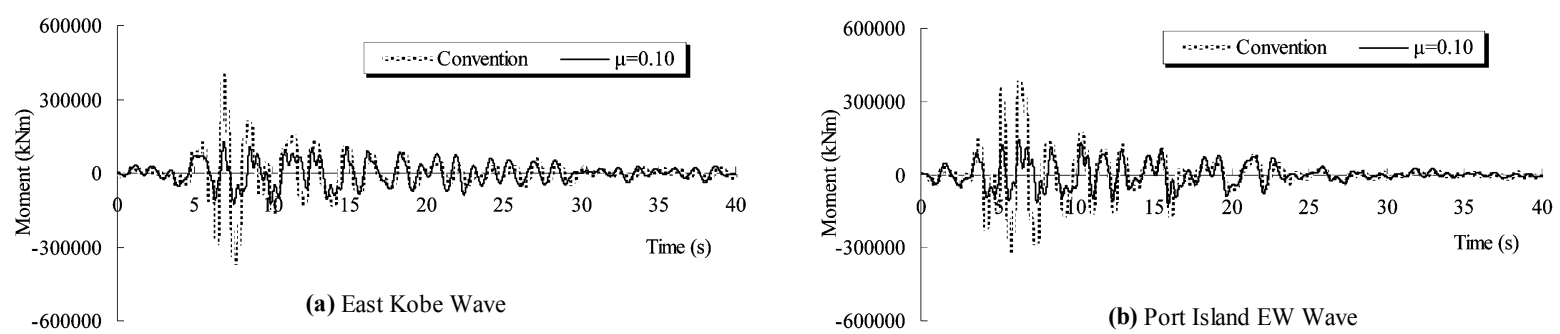

(4) Rotational reaction moment of the base spring

Fig. 6 Responses of the gravity center above the isolator and the reaction forces of the base spings

method, and the time interval of integration is $0.01 \mathrm{~s}$. As to damping, strain energy Raileigh damping is adopted in the analysis.

The earthquake inputs for the simulation are the $\mathrm{N} 12 \mathrm{~W}$ acceleration records obtained on the East Kobe-Ohashi bridge and the EW and UP-DOWN acceleration records obtained on Port Island in the 1995 Hyogo-ken Nanbu Earthquake. They are called the East Kobe Wave, the Port Island EW Wave and the Port Island UD Wave, respectively.

In the analysis, the effects of each parameter are simulated using the horizontal earthquake inputs, and the effect of vertical earthquake input is investigated at (6) as well.

\section{(2) Oscillation behavior and aseismicity}

In this analysis, two calculation cases are conducted, each of which is concerned mainly with
Table 4 Constants of the isolator

\begin{tabular}{|c|c|c|}
\hline$k_{H}\left(\mathrm{kN} / \mathrm{m}^{3}\right)$ & $k_{H 2}\left(\mathrm{kN} / \mathrm{m}^{3}\right)$ & $k_{V}\left(\mathrm{kN} / \mathrm{m}^{3}\right)$ \\
\hline $1.739 \times 10^{5}$ & $1.739 \times 10$ & $5.216 \times 10^{5}$ \\
\hline
\end{tabular}

sliding or rocking. For the case that focuses mainly on sliding, the isolator's factors are assumed to be $\mu=0.10<\ell / 3 h_{1}=0.153, \delta_{o}=2 \mathrm{~mm}, k_{H_{2}}=10^{-4} k_{H}$, $k_{v}=3 k_{H}$, and the damping ratio $h_{i}=1 \%$. Only very little value is introduced for $k_{H 2}$ in analytical convenience here. On the other hand, for the case that focuses mainly on rocking, the friction coefficient is assumed to be infinite, and the other factors of the isolator are assumed to be the same as the case that focused mainly on sliding.

Assuming $V=m_{1} g$, according to equation (12), $k_{H}, k_{H_{2}}, k_{v}$ can be obtained as shown in Table 4. 
Regarding the case focused mainly on sliding, the responses of the gravity center above the isolator and the reaction forces of the base springs are shown in Fig. 6. To compare this with a conventional structure (united structure with a plastic hinge at the column bottom), the results (the column deformation is considered in the calculations) for a conventional structure are also presented. On Fig. 6 (1), by either of the input waves, the maximum response acceleration of the isolation system is only $1.26 \mathrm{~m} / \mathrm{s}^{2}$. As the maximum response acceleration of the superstructure for the conventional structure is about $7.0 \mathrm{~m} / \mathrm{s}^{2}$, the ratio is about 0.18 . When the isolation system is adopted, the acceleration response becomes small. As shown in Fig. 6 (2), the maximum horizontal displacement caused by the East Kobe Wave is $595 \mathrm{~mm}$ and the residual displacement is $94 \mathrm{~mm}$. On the other hand, the Port Island EW Wave causes a maximum horizontal displacement of $695 \mathrm{~mm}$ and a residual displacement of merely $5 \mathrm{~mm}$. Fig. 6 (3) and Fig. 6 (4) show the reaction forces of the base springs. Using the East Kobe Wave, the maximum horizontal reaction force for the conventional structure is 30,388 $\mathrm{kN}$, but for the isolating system it reaches only $11,430 \mathrm{kN}$. Regarding the maximum rotation reaction moment, the conventional structure reaches $401,983 \mathrm{kNm}$; however, the isolating system reaches only $126,562 \mathrm{kNm}$. The responses by the Port Island EW Wave exhibit the same trend, i.e. the horizontal reaction force of the isolation system is only about $2 / 5$ that of the conventional structure. As for the rotation reaction, the ratio is only $1 / 3$.

As mentioned above, it is clear that the isolation system has greater aseismicity in the case focused mainly on sliding.

As an example, the oscillation behaviors are explained by the results of the Port Island EW Wave. The rotation angle and the relative displacement between the superstructure and the foundation raft are shown in Fig. 7. Due to the isolator's rotation angle being small, the maximum is only $2.43 \mathrm{mrad}$ as shown in Fig. 7 (b), therefore almost all the relative horizontal displacement was caused by the isolator's sliding as shown in Fig. 7 (a), i.e. the vibration is a sliding movement. According to Fig. 8, the maximum vertical acceleration above the isolator reaches $0.71 \mathrm{~m} / \mathrm{s}^{2}$, and the maximum angular acceleration above the isolator is $0.45 \mathrm{rad} / \mathrm{s}^{2}$.

Fig. 9 shows the oscillation behavior of the isolator. The maximum sliding velocity is $1.39 \mathrm{~m} / \mathrm{s}$, and the movement is relatively slow as shown in Fig. 9 (1). Because the friction coefficient is 0.10 , the sheer force acting on the isolator levels off at about 3,900 $\mathrm{kN}\left(\mu m_{l} g\right)$ as shown in Fig. 9 (2) (a). According to Fig. 9 (3), the maximum normal stress of the isolator

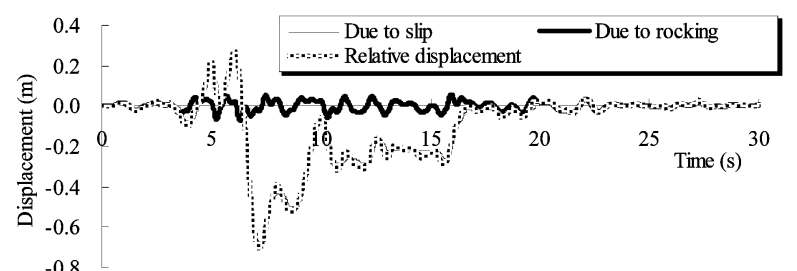

(a) Relative horizontal displacement of the superstructure

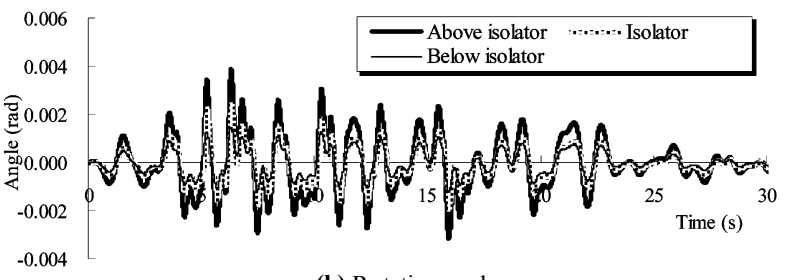

(b) Rotation angle

Fig. 7 Relative displacement and rotation angle

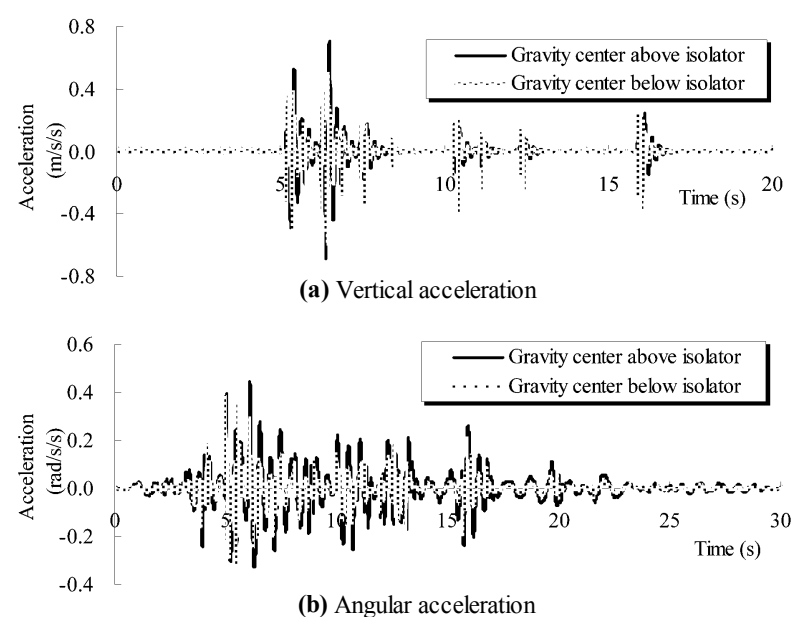

Fig. 8 Vertical and angular accelerations

is $10,085 \mathrm{kPa}$, the mean stress caused by the dead load is $3,477 \mathrm{kPa}$, the ratio is less than 3 times, and the maximum exfoliative width of the footing is only $6.0 \mathrm{~mm}$. As shown in Fig. 9 (4), the footing's maximum lift-off ratio is 0.20 of the footing's whole width, less than $50 \%$ of the permissible value for a spread foundation of level 1 seismic design, as provided in Specifications for Highway Bridges. The hysteretic curves of the isolator are shown in Fig. 9 (5); the sliding force $\sim$ displacement curve is bilineary. Moreover, because the restoration power is limited, the inclination between the sliding force and the sliding displacement is almost 90 degrees. Meanwhile, because the footing rarely experienced lift-off, the hysteretic curve of the rotation moment $\sim$ angle is nearly a straight line.

The isolation system has two methods of earthquake energy dissipation; one is by sliding friction, and the other is by rocking vibration. The amount of energy dissipated may be calculated by equation (16), the results of which are shown in Fig. 10. As the hysteretic curve of the rotation moment- angle is 

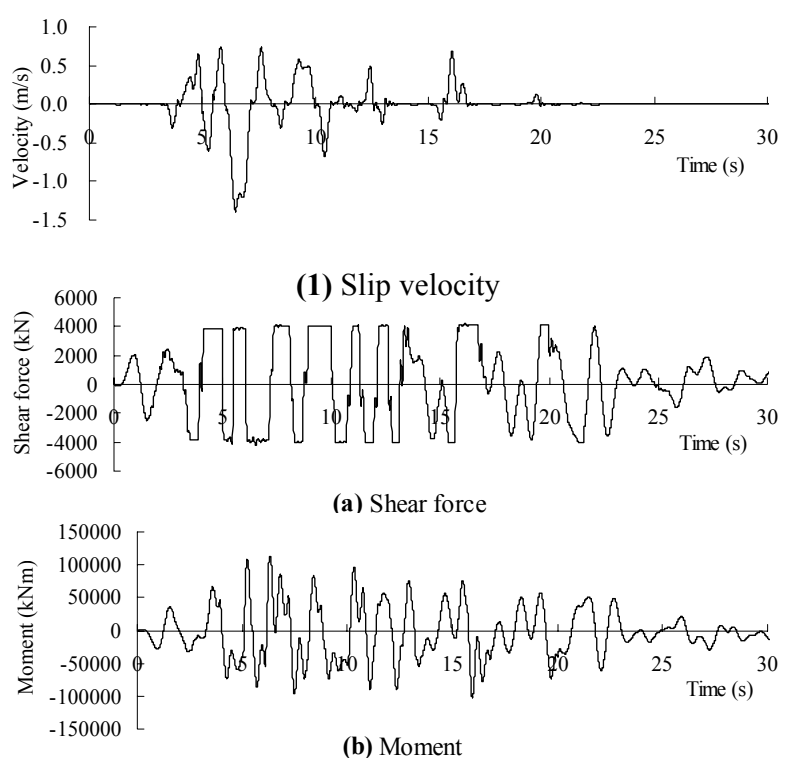

(2) Forces acting at the isolator Ratio of distance from footing's center to footing's width

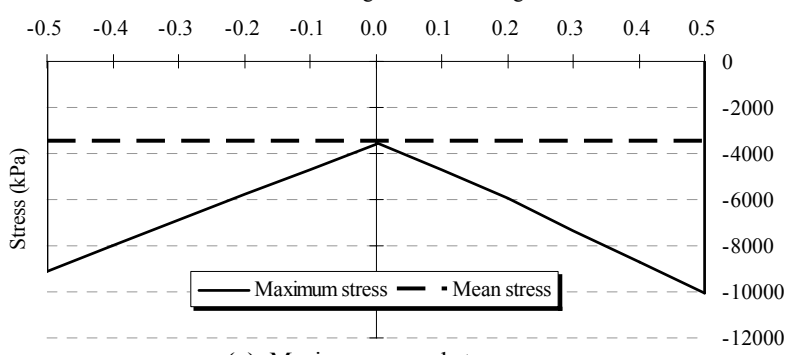

(a) Maximum normal stress

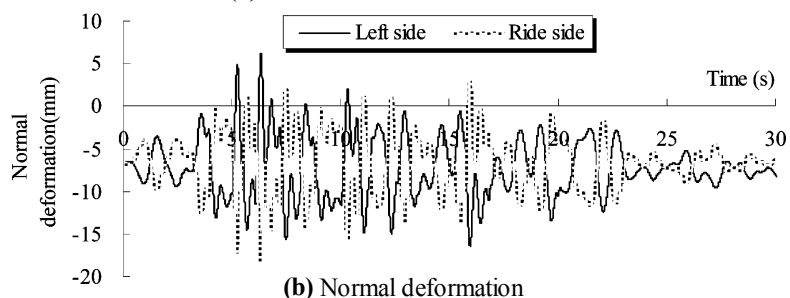

(3) Isolator's stress and deformation Ratio of distance from footing's center to footing's width

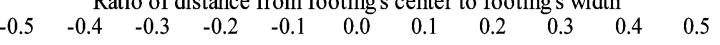

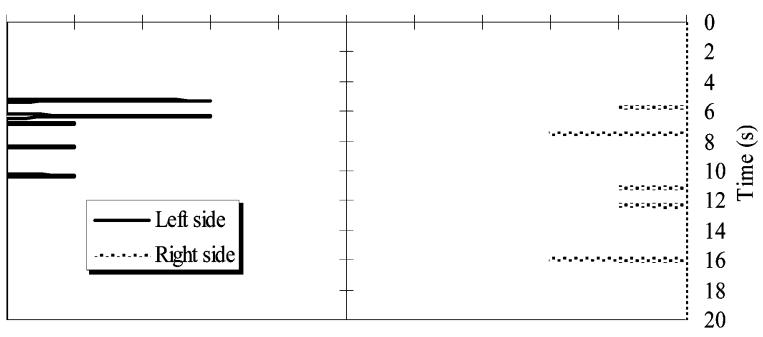

(4) Footing's lift-off ratio

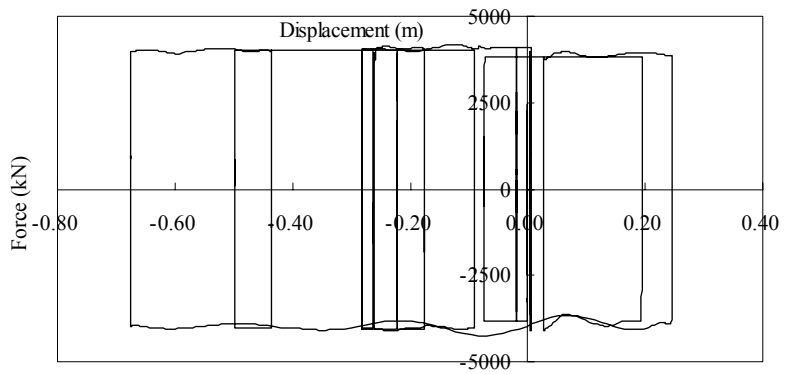

(a) Sliding force $\sim$ displacement

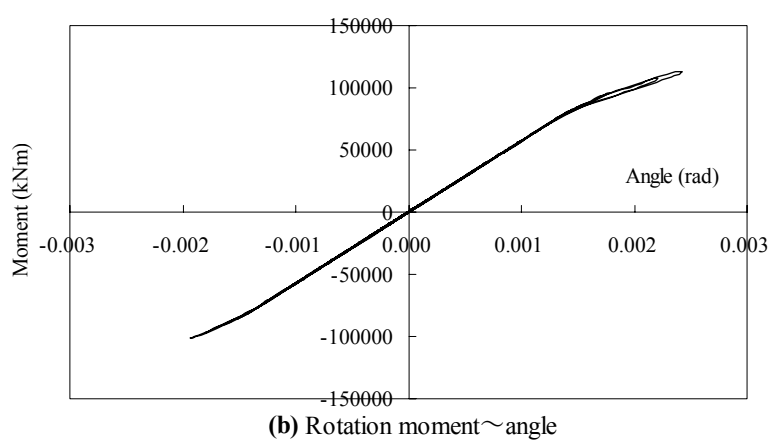

(5) Hysteretic curve

Fig. 9 Oscillation behavior of the isolator

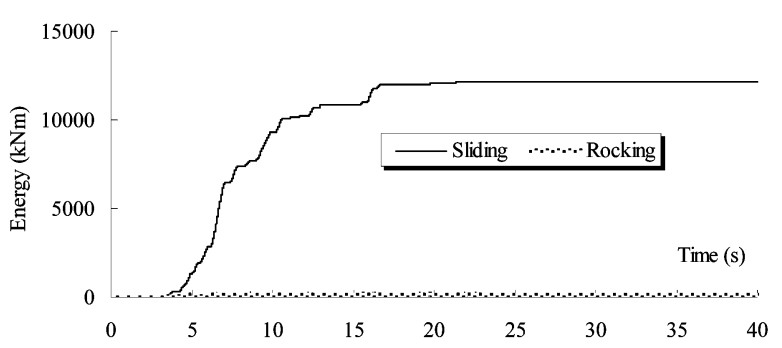

Fig. 10 History of the accumulation of energy's absorption

nearly a straight line, the energy absorption is almost entirely by sliding friction.

$$
\left.\begin{array}{l}
E_{s}=\int_{t} F(t) \cdot d(S(t)) \\
E_{R}=\int_{t} M(t) \cdot d(\theta(t))
\end{array}\right\}
$$

Where $E_{s}$ is the dissipation energy by sliding friction and $E_{R}$ is that by rocking vibration, respectively, $F(t)$ is the friction force and $M(t)$ is the rotation moment acting on the isolator. $S(t)$ is the sliding displacement and $\theta(t)$ is the rotation angle of the isolator.

Meanwhile for the mainly rocking case, for example, the response by the Port Island EW Wave is introduced. The horizontal response time history of the gravity center above the isolator and the reaction of the base springs are shown in Fig. 11. The results for a conventional structure are also illustrated. Regarding the maximum response acceleration, that of the conventional structure is $7.03 \mathrm{~m} / \mathrm{s}^{2}$, while that of the isolation system is $6.12 \mathrm{~m} / \mathrm{s}^{2}$ as shown in Fig. 11 (a); the ratio is 0.87 . Regarding rocking vibration, if the rotation angle is not too large, namely less than the overturning critical angle, the self-weight becomes the restoration power. The oscillation is like a swing of a reverse pendulum, and the residual displacement is hardly calculable as shown in Fig. 11 (b). The reaction forces of the foundation springs of the isolating and the conventional structure are shown in Figs. 11 (c) and (d). As for the maximum horizontal reaction force, that of the isolation system is about $81 \%$ of the conventional structure. Whereas, regarding the maximum rotation reaction moment, that of the isolation system is about $74 \%$ of the conventional structure. 

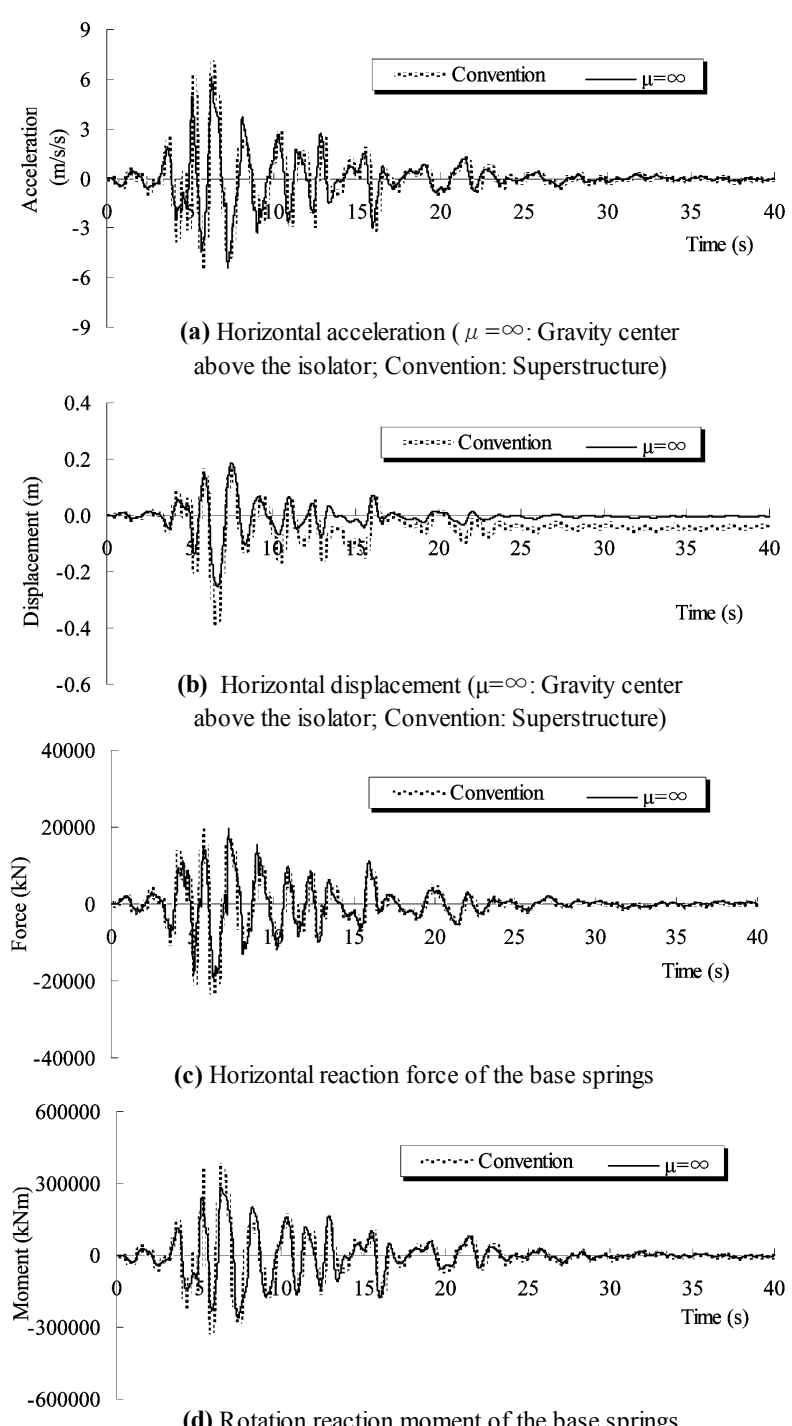

Fig. 11 Response of the gravity center above the isolator and reaction forces of the base spings

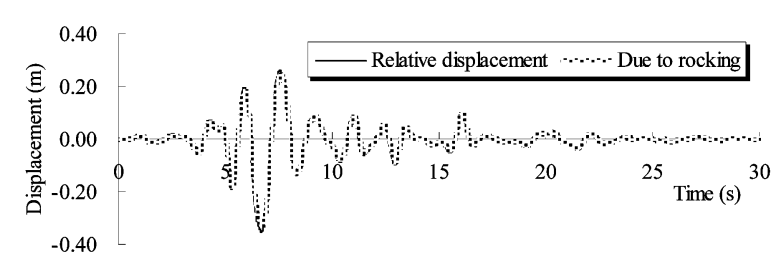

(a) Relative horizontal displacement of the superstructure

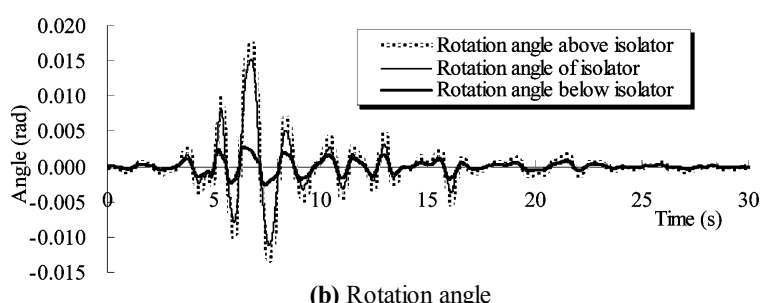

Fig. 12 Relative displacement and rotation Angle

The oscillation behavior of the case involving mainly rocking can be investigated in Figs. 12-15. Fig. 12 (a) shows the relative displacement betweenthe superstructure and the foundation raft.
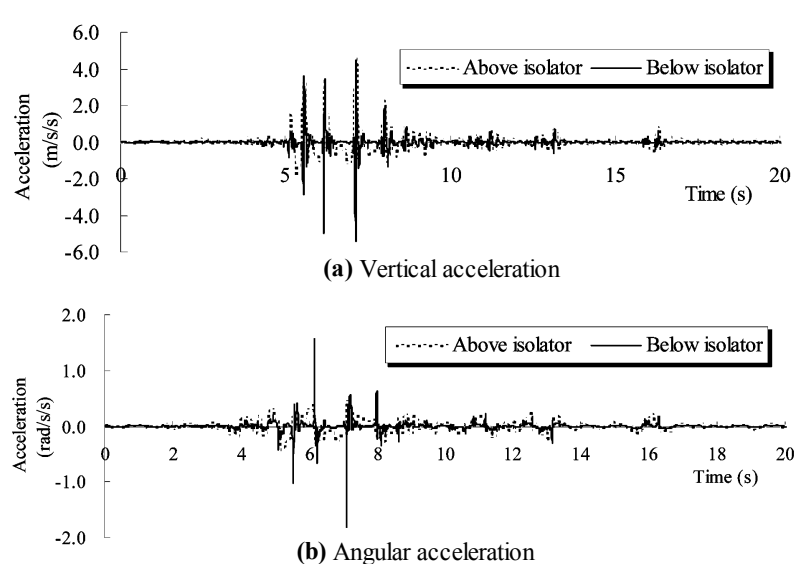

Fig. 13 Vertical and angular accelerations

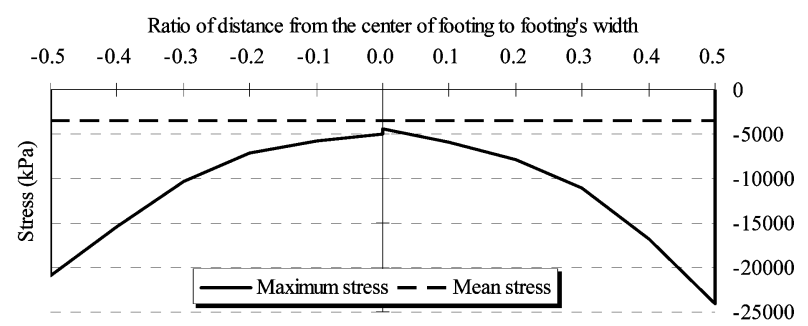

(a) Maximum normal stress

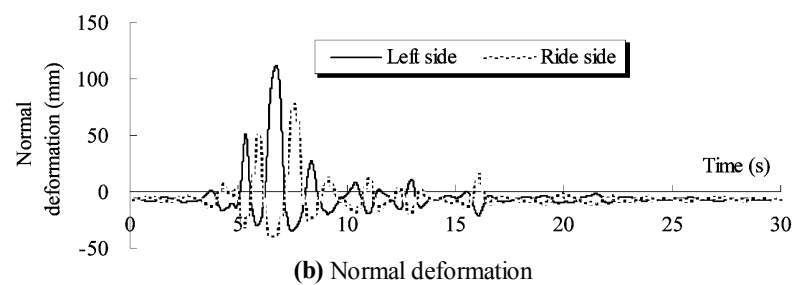

(1) Isolator's stress and deformation

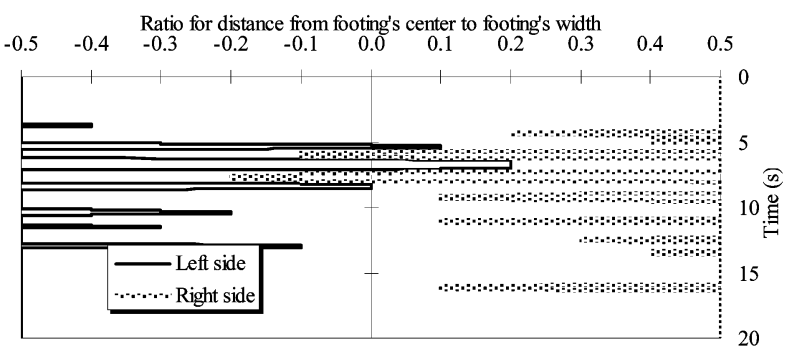

(2) Footing's lift-off ratio

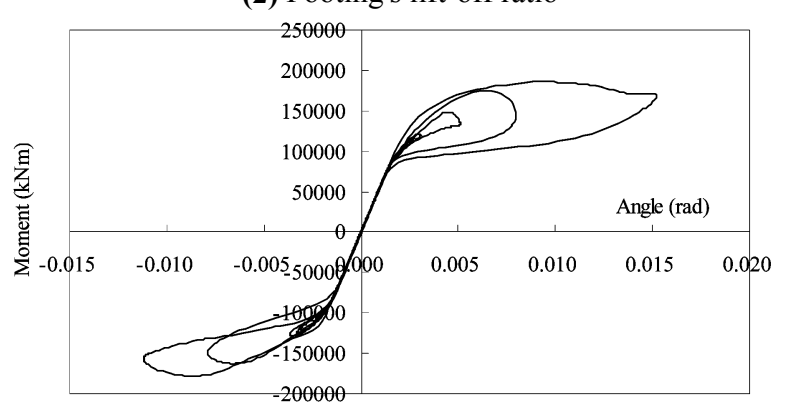

(3) Rotation moment $\sim$ angle

Fig. 14 Oscillation behavior of the isolator

Almost all the relative displacement is caused by the isolator's rocking. In Fig. 12 (b), it is clear that the isolator's rotation angle is almost entirely caused by the rocking of the structure above the isolator. The vertical acceleration and the rotation acceleration are 


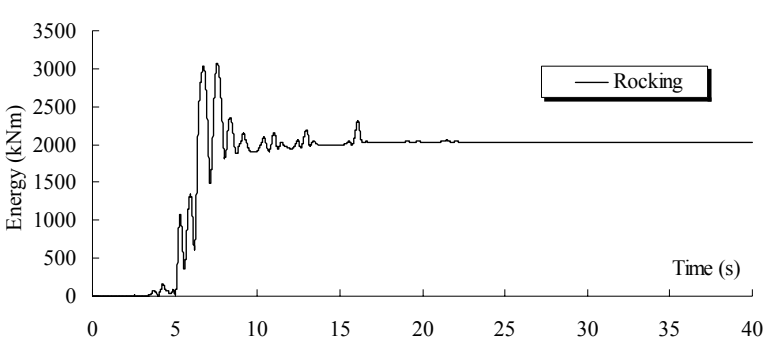

Fig. 15 History of the accumulation of energy's absorption

shown in Fig. 13. The maximum vertical acceleration reaches $4.53 \mathrm{~m} / \mathrm{s}^{2}$ above the isolator, and $5.40 \mathrm{~m} / \mathrm{s}^{2}$ below the isolator. Regarding the rotation acceleration, the maximum above the isolator reaches 0.45 $\mathrm{rad} / \mathrm{s}^{2}$, while the maximum below the isolator reaches $1.80 \mathrm{rad} / \mathrm{s}^{2}$. Fig. 14 shows the oscillation behavior of the isolator. The maximum normal stress is 24,058 $\mathrm{kPa}$, about 7 times the mean stress as calculated by the dead load, and the maximum exfoliative width of the footing is $111.5 \mathrm{~mm}$ as shown in Fig. 14 (1). The footing's maximum lift-off ratio is $70 \%$ of the footing's whole width as shown in Fig. 14 (2). Due to the footing's lift-off, the hysteretic curve of the rotation moment-angle shows a non-linear property. Furthermore, the hysteretic curve tends toward the starting point of the lift- off due to the self-weight component of the pier as shown in Fig. 14 (3). The accumulation of energy dissipation by rocking vibration is shown in Fig. 15.

As previously discussed, the isolating structure, be it the mainly sliding one or the mainly rocking one, has excellent aseismicity. As to the mainly sliding structure, the stress acting on the isolator is not large; consequently, the demand for the bearing force is low. On the other hand, for the mainly rocking one, the stress is large, and the vertical acceleration is not small either. However, the residual displacement is hardly calculable.

\section{(3) Effects of the friction coefficient}

The friction coefficient is assumed to be $0.10,0.15$, $0.20,0.30$, and $\infty(1.0)$, and the spring constants of the isolator in the analysis are presented in Table 4. These design values could be obtained through the selection of the isolating materials. A small friction coefficient such as 0.10 can be obtained by PTFE and a friction coefficient such as that around 0.30 can possibly be obtained by sand or gravel. In summary, the friction coefficient and spring constants of the isolator can be obtained by the selection of thickness, strength, granular size and granular shape of the material.

The maximum response displacement is shown in Fig. 16. In Fig. 16 (a), by input of either the East Kobe Wave or the Port Island EW Wave, the horizontal
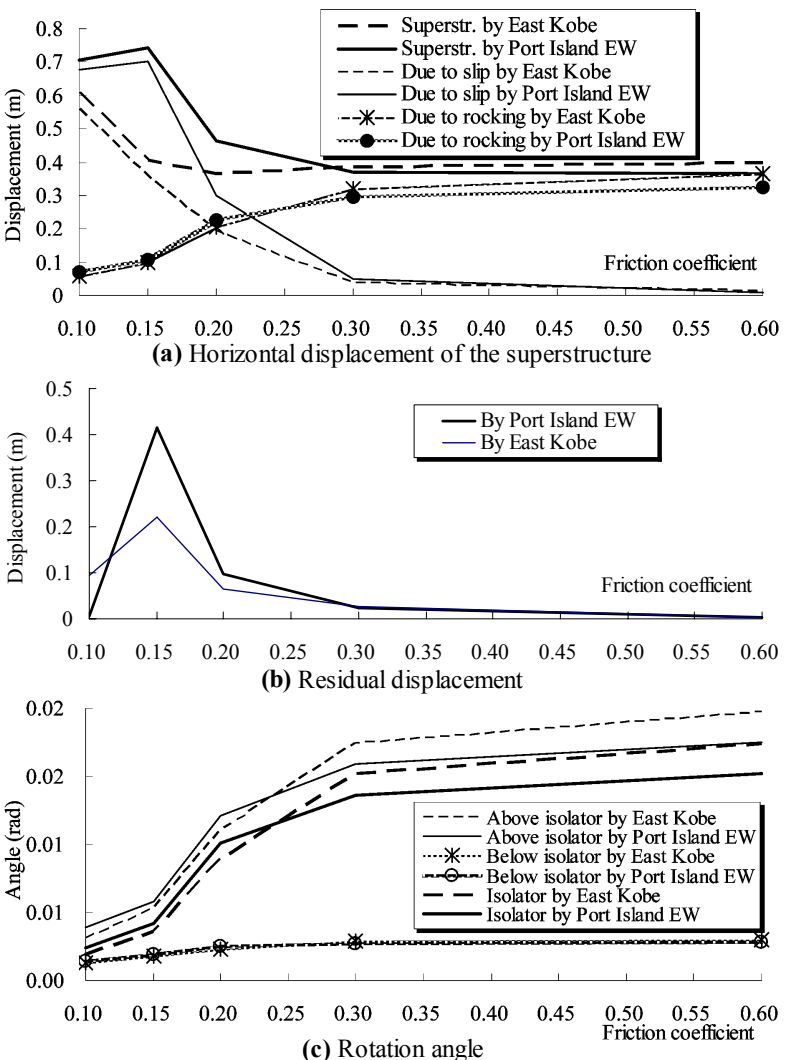

Fig. 16 Response displacement

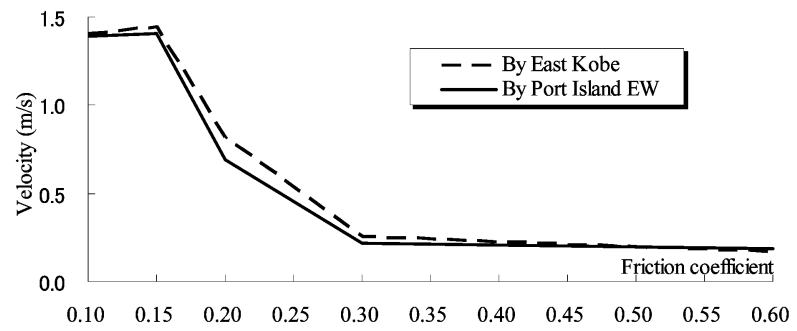

Fig. 17 Slip velocity

displacement of the superstructure is mainly calculated by slip where $\mu<0.15$, which is mostly brought about by rocking where $\mu>0.30$; and where $\mu=$ 0.20 , the displacement by slip is nearly equal to that by rocking. It is thought that a sliding vibration dominates where $\mu<\ell / 3 h_{1}=0.153$ by equation (13), a rocking vibration dominates where $\mu>2 \ell / 3 h_{1}=0.31$, and a sliding-rocking vibration may occur where $\ell / 3 h_{1}<\mu<2 \ell / 3 h_{1}$. In Fig. 16 (b), for a sliding vibration, the residual displacement tends to be larger as the friction coefficient increases; on the other hand, small residual displacement remains for rocking vibration. When $\mu$ is small, the force against a bridge pier movement is small, thereby, it exhibits a tendency that the residual displacement is small as $\mu$ is small; and in a rocking vibration, the self-weight becomes the restoration power. In Fig. 16 (c), the rotation angle increases with the increase of the friction coefficient, but where 


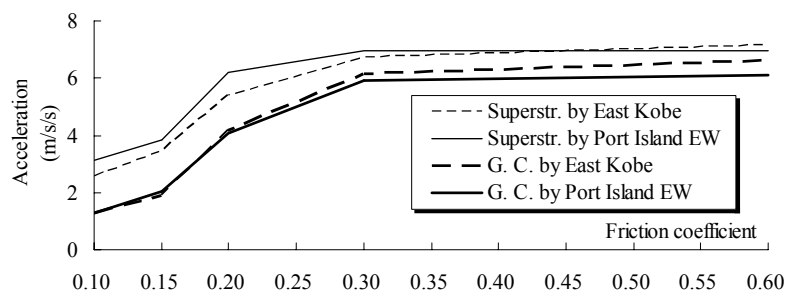

(a) Horizontal acceleration of the superstructure and the gravity center above the isolator

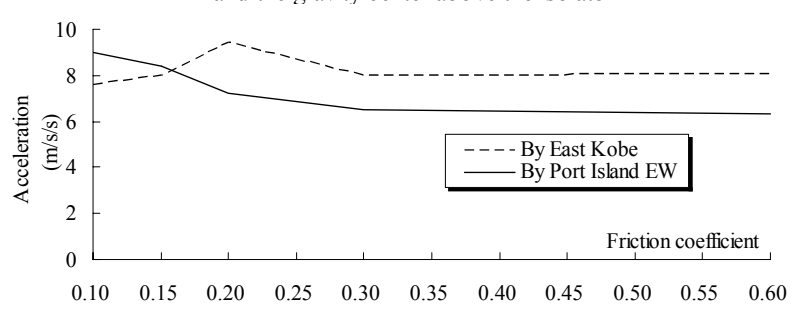

(b) Horizontal acceleration of the gravity center
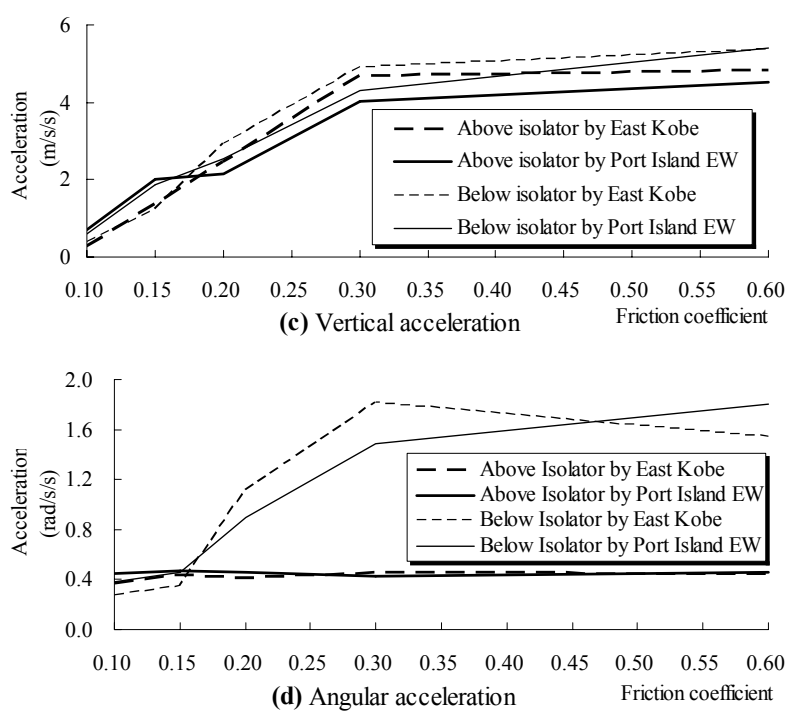

Fig. 18 Response acceleration
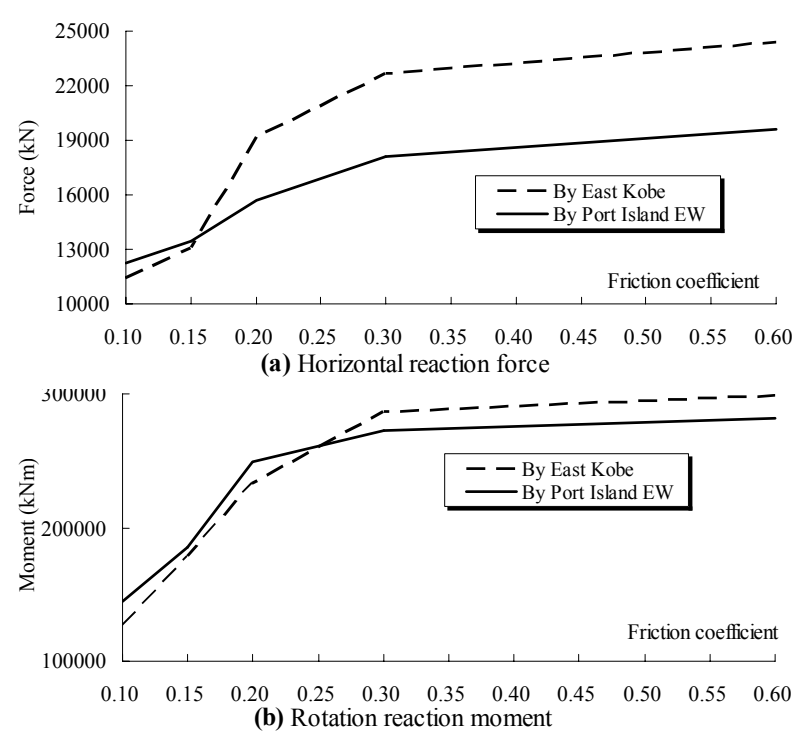

Fig. 19 Reaction forces of the base springs

$\mu>0.30$, the rotation angle is almost constant, and the isolator's rotation angle is mainly brought about from rocking above the isolator.
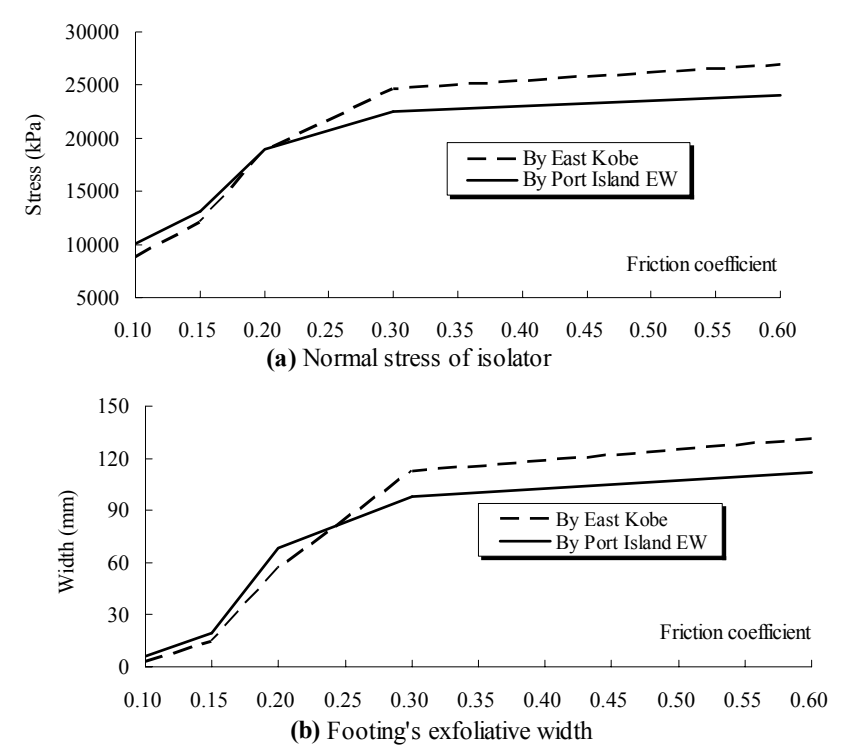

Fig. 20 Isolator's normal stress and footing's exfoliative width

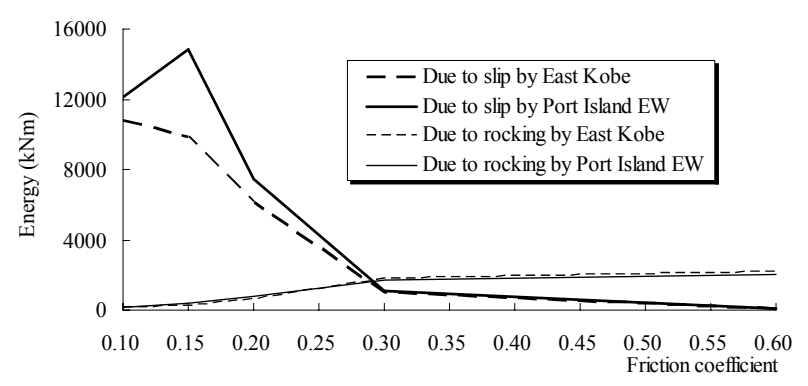

Fig. 21 Absorption of energy

As shown in Fig. 17, the maximum slip velocity is almost a constant in the mainly sliding vibration, and in the sliding-rocking vibration, the speed decreases as the friction coefficient increases. The maximum response acceleration is shown in Fig. 18. As in Figs. 18 (a) and (c), the horizontal acceleration above the isolator and the vertical acceleration increase as the friction coefficient increases; but these increases are reduced in the rocking vibration; the angular acceleration below the isolator shows the same tendency as shown in Fig. 18 (d). Meanwhile, the friction coefficient does not affect the response of horizontal acceleration below the isolator and angular acceleration above the isolator as shown in Figs. 18 (b) and (d). Fig. 19 shows the maximum base spring reaction forces, and Fig. 20 shows the normal stress of the isolator and the footing's maximum exfoliative width. The responses mentioned above increase as the friction coefficient increases, but these increases are reduced in the rocking vibration. It is thought that absorption energy due to sliding decreases with the increase of the friction coefficient, and the absorption energy due to rocking does not change as much in the rocking vibration as shown in Fig. 21.

These results suggest that the friction coefficient 
Table 5 Ratio of $\ell / 3 h_{1} \quad h_{1}=12.0 \mathrm{~m}$

\begin{tabular}{|c|r|r|r|}
\hline $2 \ell(\mathrm{m})$ & 11.00 & 12.50 & 14.50 \\
\hline $2 \ell / h_{1}$ & 0.917 & 1.042 & 1.208 \\
\hline$\ell / 3 h_{1}$ & 0.153 & 0.174 & 0.201 \\
\hline
\end{tabular}

Table 6 Constants of the isolator

\begin{tabular}{|c|r|r|r|}
\hline $2 \ell(\mathrm{m})$ & $k_{H}\left(\mathrm{kN} / \mathrm{m}^{3}\right)$ & $k_{H 2}\left(\mathrm{kN} / \mathrm{m}^{3}\right)$ & $k_{V}\left(\mathrm{kN} / \mathrm{m}^{3}\right)$ \\
\hline 11.00 & $1.739 \times 10^{5}$ & $1.739 \times 10$ & $5.216 \times 10^{5}$ \\
\hline 12.50 & $1.530 \times 10^{5}$ & $1.530 \times 10$ & $4.590 \times 10^{5}$ \\
\hline 14.50 & $1.319 \times 10^{5}$ & $1.319 \times 10$ & $3.957 \times 10^{5}$ \\
\hline
\end{tabular}

greatly affects the isolating structure's oscillation mode. Where $\mu<\ell / 3 h_{1}$, the oscillation will be a mainly sliding one, and if $\mu>2 \ell / 3 h_{1}$, the oscillation is a mainly rocking one. Moreover, the residual displacement has a tendency to increase as the friction coefficient increases in a mainly sliding oscillation.

\section{(4) Effects of the ratio of $m_{1}$ 's height to footing width}

The ratio for $\ell / 3 h_{1}$ is considered to vary from 0.153 to 0.201 as presented in Table 5. According to Eq. (15), the minimum of $\ell / 3 h_{1}$ is 0.15 , thus the lower value is adopted as 0.153 , and the upper valueis assumed to be 1.3 times the lower one in this analysis. The factors of the isolator are calculated by providing $\mu=0.10, \delta_{o}=2 \mathrm{~mm}, k_{H 2}=10^{-4} k_{H}$, $k_{v}=3 k_{H}$ as presented in Table 6 in the analysis. The friction coefficient is assumed to be 0.10 and 0.15 .

The result by the Port Island EW Wave is illustrated here as an example. The response displacements are shown in Fig. 22. As the ratio for $\ell / 3 h_{1}$ increases, the horizontal displacements of the superstructure and the residual displacement increase, especially where $\mu=0.15$ as shown in Figs. 22 (a) and (b). On the other hand, the horizontal displacement by rocking and the rotation angle reduce as the ratio for $\ell / 3 h_{1}$ increases as shown in Figs. 22 (c) and (d).

Fig. 23 shows the maximum response acceleration above the isolator, the horizontal acceleration has a little reduction, but the vertical acceleration decreases considerably as the ratio for $\ell / 3 h_{1}$ increases. The vertical acceleration for $\ell / 3 h_{1}=0.201$ is $1 / 2$ that for $\ell / 3 h_{1}=0.153$. The maximum reaction force of the base spring is shown in Fig. 24. The horizontal reaction force decreases, conversely, while the rotation increases as the ratio for $\ell / 3 h_{1}$ increases. It is thought that with the increase of the footing's width, the sliding vibration also increases, the vertical acceleration becomes small, and both the vertical
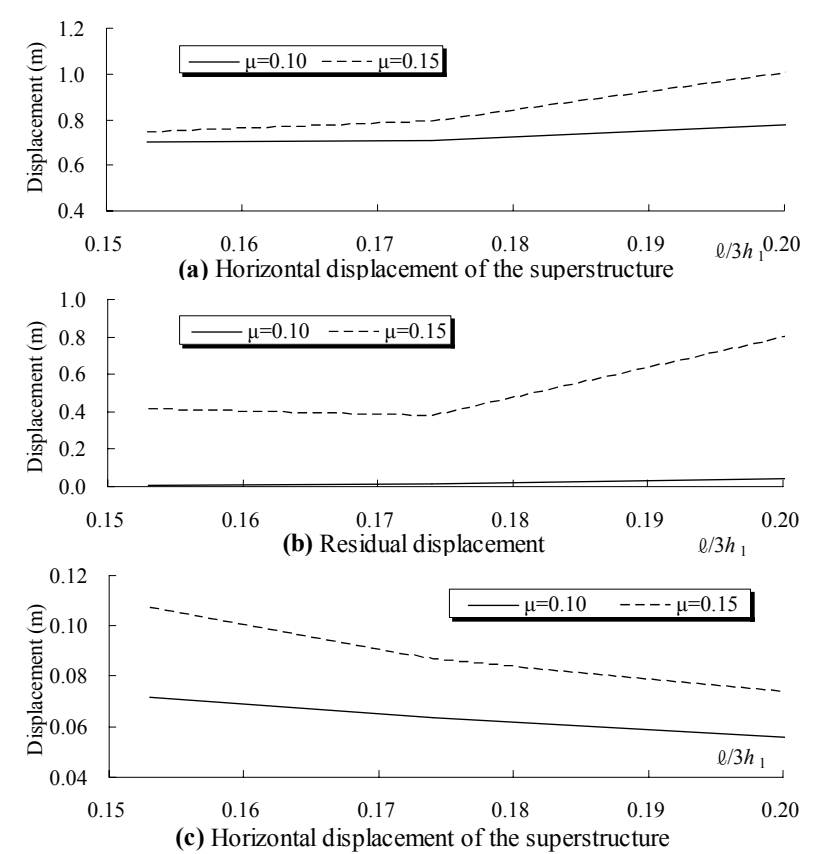

(c) Horizontal displacement of the superstructure due to rocking

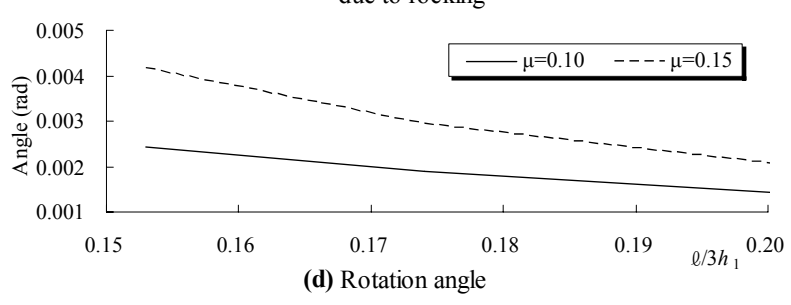

Fig. 22 Response displacement
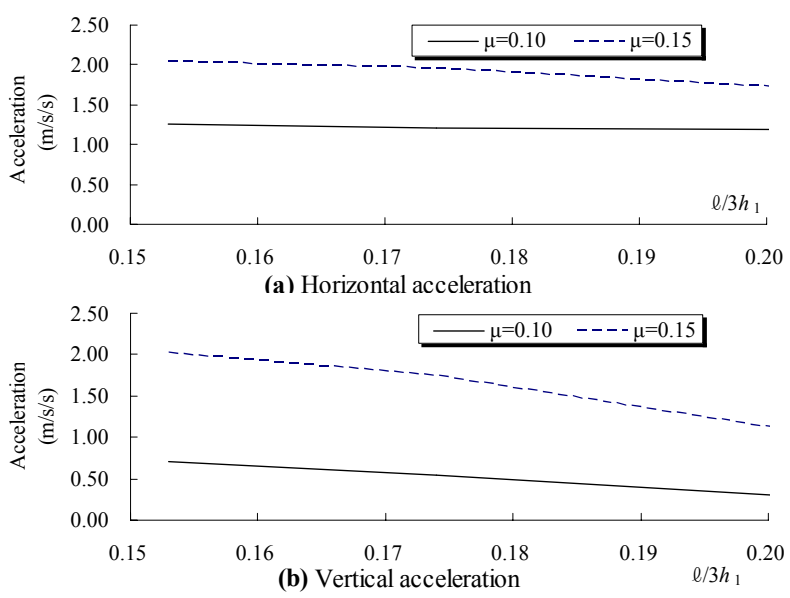

Fig. 23 Acceleration of the gravity center above the isolator

reaction force $V$ and the horizontal force $H=\mu V$ decreases; hence, the lateral load from the portion above the isolator decreases. Meanwhile, owing to the increase of the inertial moment of the base of the footing, the rotation resistant moment of the isolator increases; therefore, the rotation moment from the portion above the isolator increases. For the same reason, either the normal stress or the exfoliative width decreases with the increase of the footing width as shown in Fig. 25. 

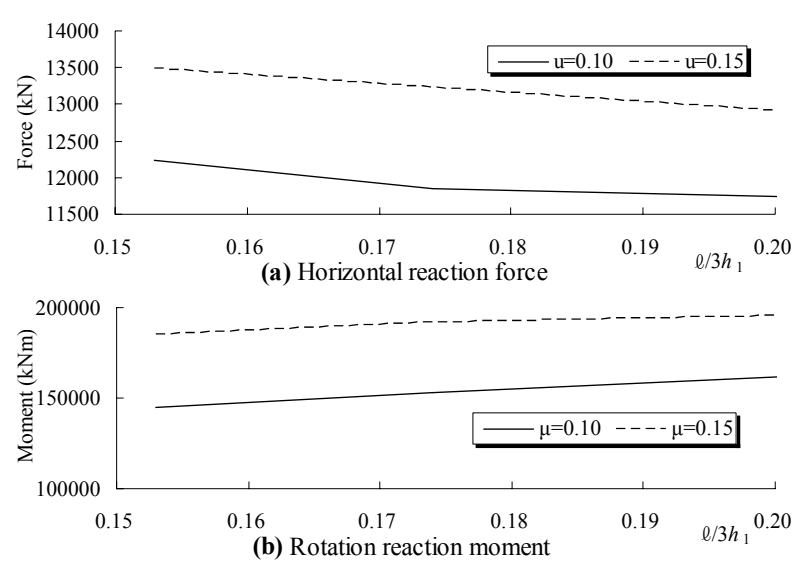

Fig. 24 Reaction forces of the base springs
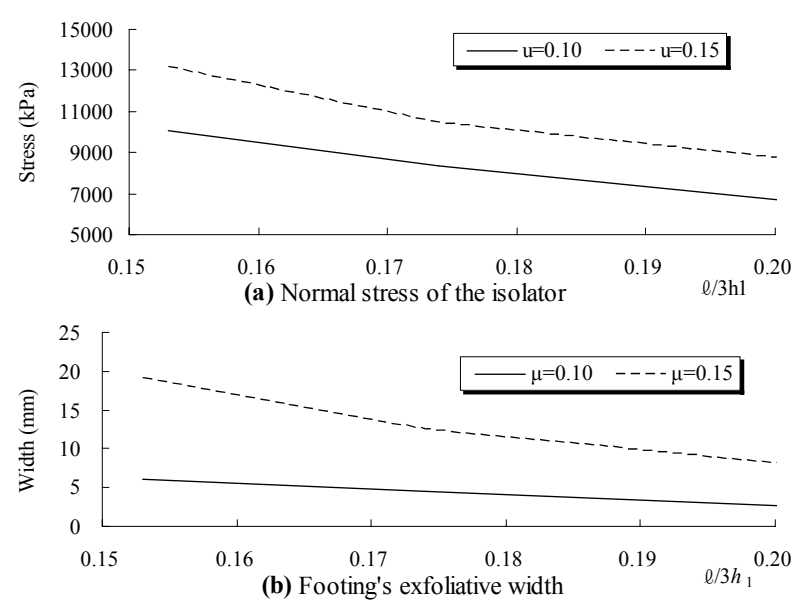

Fig. 25 Isolator's normal stress and footing's exfoliative width

Table 7 Constants of the isolator

\begin{tabular}{|c|r|r|r|}
\hline$\delta_{\mathrm{o}}(\mathrm{mm})$ & $k_{H}\left(\mathrm{kN} / \mathrm{m}^{3}\right)$ & $k_{H 2}\left(\mathrm{kN} / \mathrm{m}^{3}\right)$ & $k_{V}\left(\mathrm{kN} / \mathrm{m}^{3}\right)$ \\
\hline 1.0 & $3.477 \times 10^{5}$ & $3.477 \times 10$ & $5.216 \times 10^{5}$ \\
\hline 2.0 & $1.739 \times 10^{5}$ & $1.739 \times 10$ & $5.216 \times 10^{5}$ \\
\hline 4.0 & $8.693 \times 10^{4}$ & 8.693 & $5.216 \times 10^{5}$ \\
\hline 10.0 & $3.477 \times 10^{4}$ & 3.477 & $5.216 \times 10^{5}$ \\
\hline 20.0 & $1.739 \times 10^{4}$ & 1.739 & $5.216 \times 10^{5}$ \\
\hline
\end{tabular}

These results suggest that for mainly sliding oscillation, the sliding mode is more distinguished and the vertical acceleration decreases with the increase of the ratio for $\ell / 3 h_{1}$, while the stress acting on the isolator also decreases.

\section{(5) Effects of the yield displacement of springs}

In order to investigate the effects of the spring property, the yield displacement of the springs at the isolator is assumed to be $\delta_{o}=1 \mathrm{~mm}, 2 \mathrm{~mm}, 4 \mathrm{~mm}$, $10 \mathrm{~mm}$ and $20 \mathrm{~mm}$. Given a friction coefficient of $\mu=0.10$, the spring constants are presented in Table 7. The vertical spring constant $k_{\mathrm{V}}$ is assumed to be $3 k_{\mathrm{H}}$. As an example, the result caused by the Port

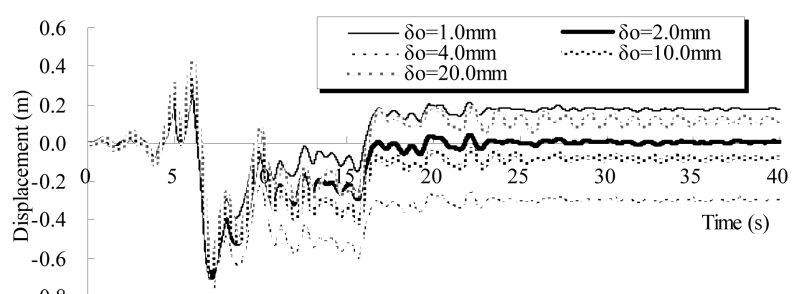

(a) Time history of the horizontal displacement of the superstructure

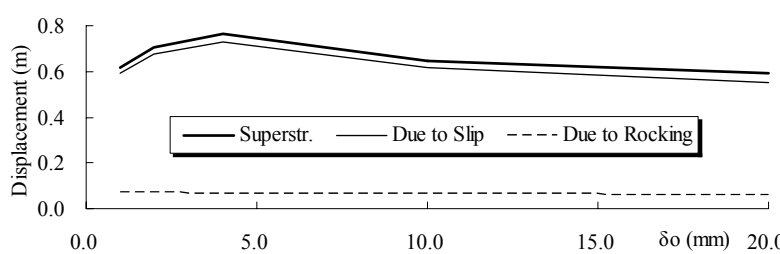

(b) Horizontal displacement of the superstructure

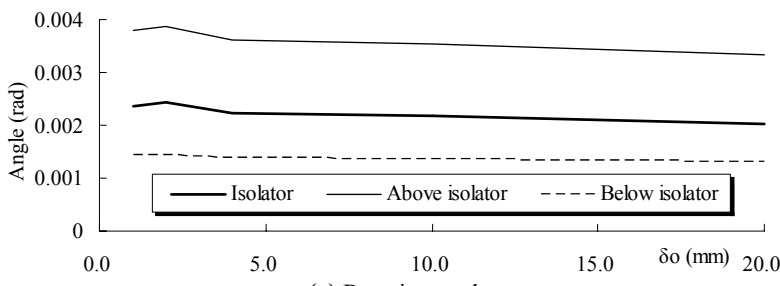

(c) Rotation angle

Fig.26 Response displacement

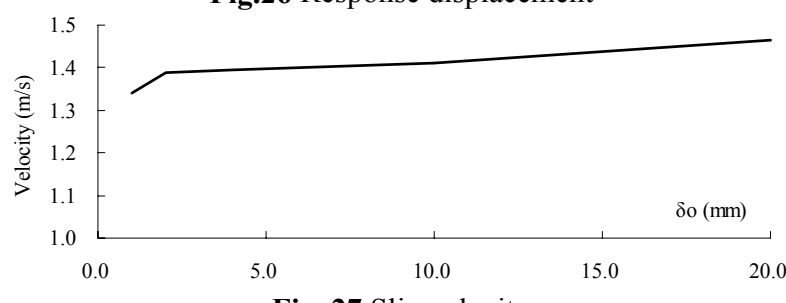

Fig. 27 Slip velocity

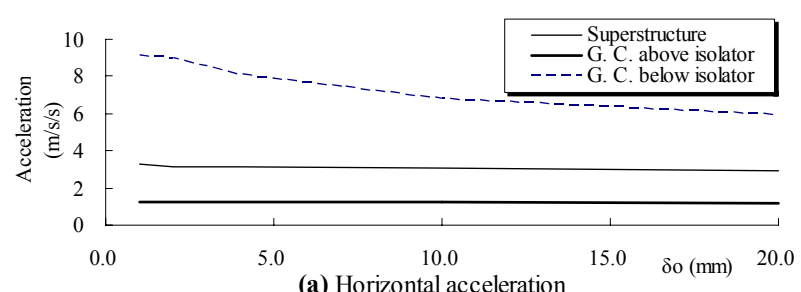

(a) Horizontal acceleration
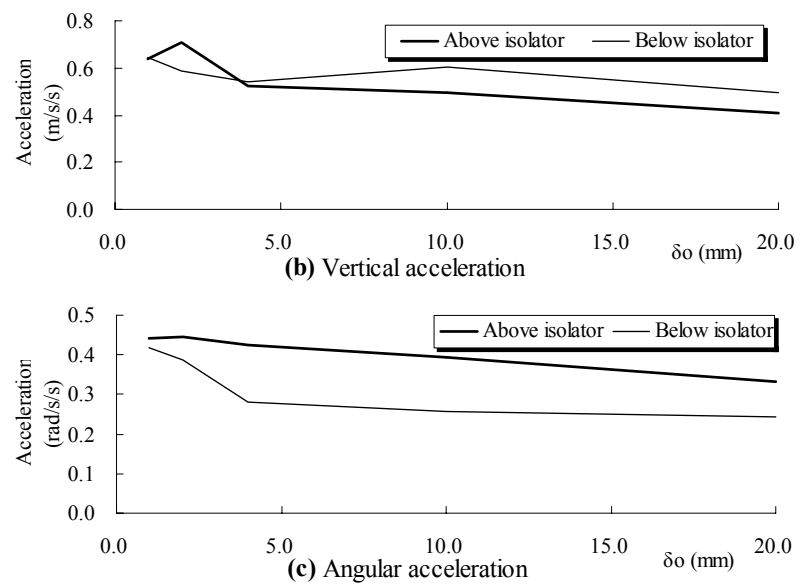

Fig. 28 Response acceleration

Island EW Wave where $\mu=0.10$ is explained.

The response displacement is shown in Fig. 26. 

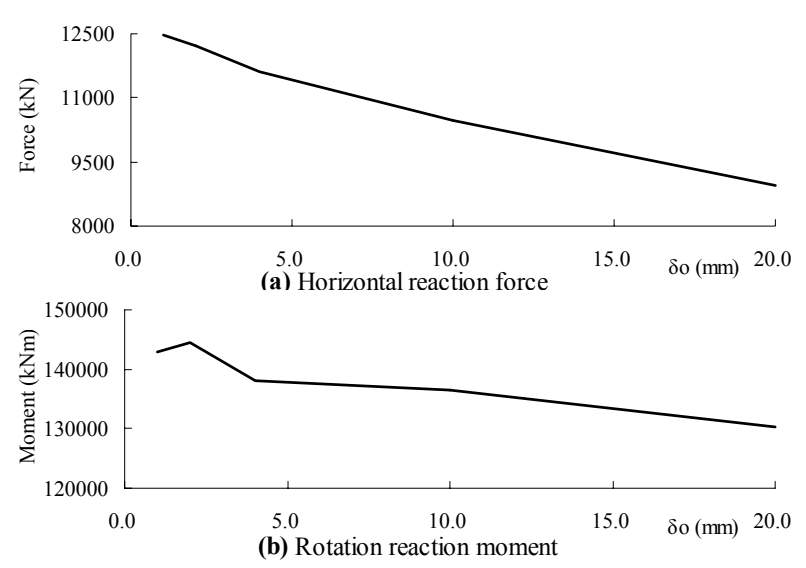

Fig. 29 Reaction forces of the base Springs
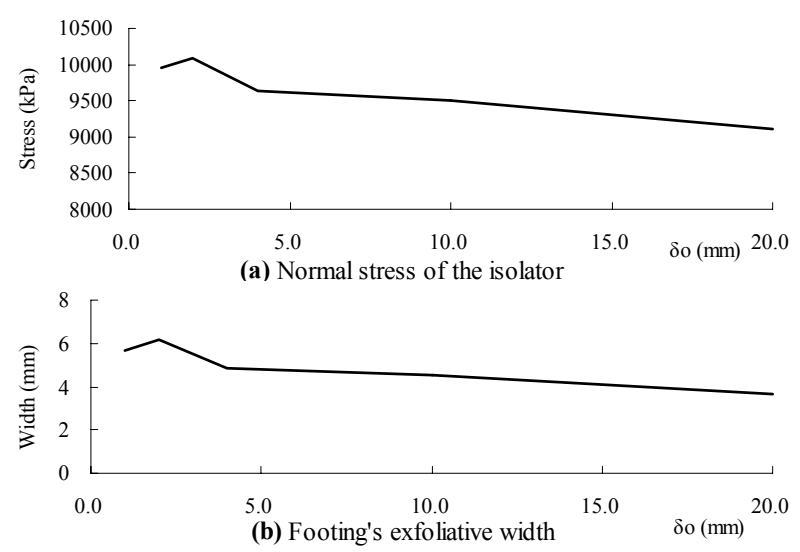

Fig. 30 Isolator's normal stressand footing's exfoliative width

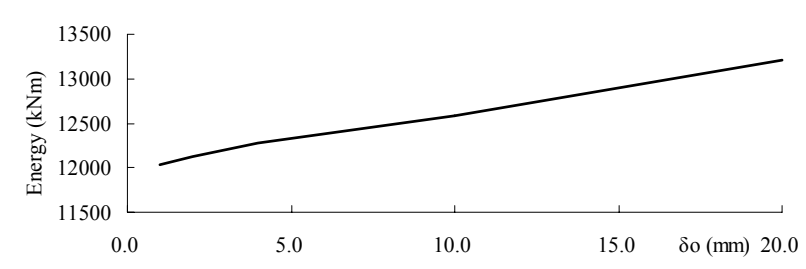

Fig. 31 Absorption of energy

The yield displacement affects the residual displacement rather than the maximum displacement as shown in Fig. 26 (a). According to Figs. 26 (b) and (c), the maximum displacement and the rotation angle tend to increase, when the yield displacement is less than $4.0 \mathrm{~mm}$; otherwise, they decrease in a narrow range as the yield displacement increases. On the other hand, the maximum velocity increases as shown in Fig. 27. The acceleration response is shown in Fig. 28. The horizontal accelerations of the superstructure and the gravity center above the isolator hardly change; nevertheless, the horizontal acceleration of the gravity center below the isolator shows a significant decrease. It is thought that the maximum acceleration of the portion above the isolator is dominated by the friction coefficient and that of the portion below the isolator is affected by the connection springs; as the horizontal spring constant

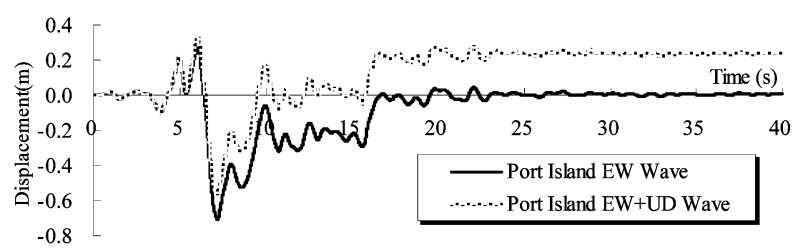

(a) Horizontal displacement of the superstructure

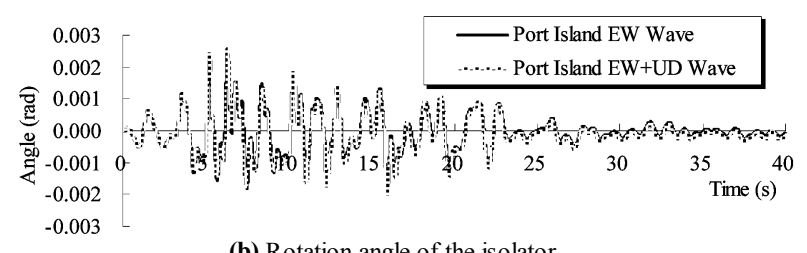

(b) Rotation angle of the isolator

Fig. 32 Response displacement

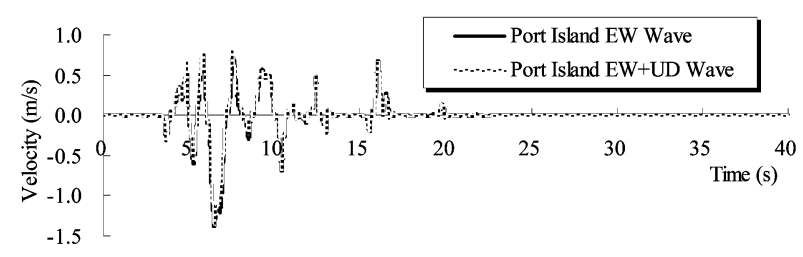

Fig. 33 Slip velocity

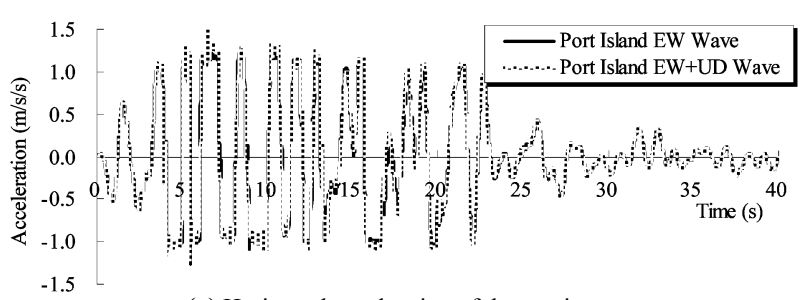

(a) Horizontal acceleration of the gravity center

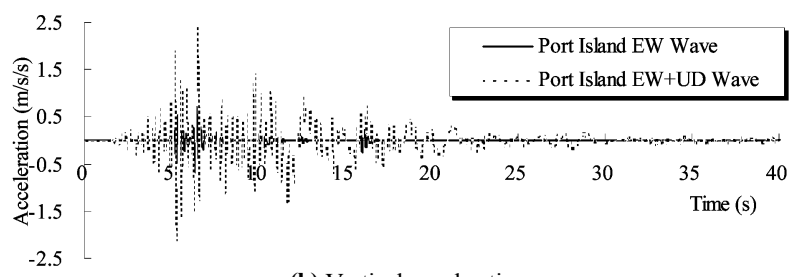

(b) Vertical acceleration

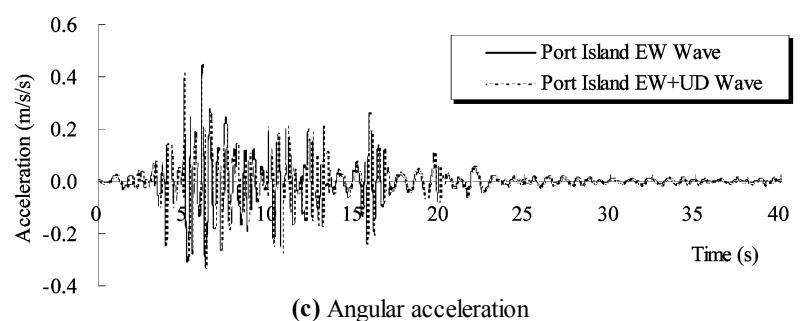

Fig. 34 Acceleration above the isolator

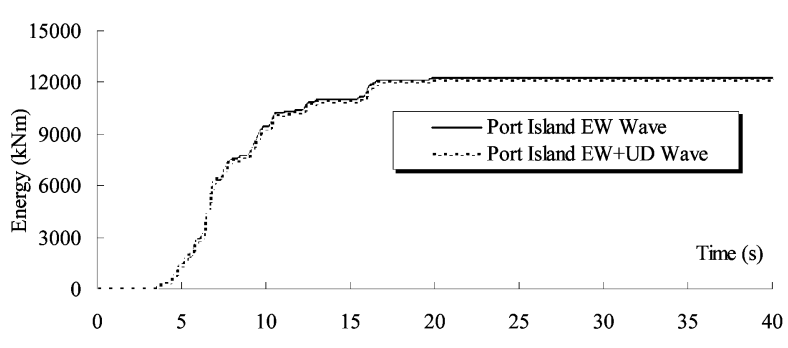

Fig. 35 Absorption of energy due to sliding 
decreases, the mutual influence of the portions above and below the isolator becomes small. Meanwhile, due to the decrease of the horizontal spring constant, the lateral deformation of the isolator becomes larger and the vertical and angular acceleration become smaller. Because of the increase in energy absorption as shown in Fig. 31, the reaction force of the base spring, the normal stress of the isolator and the exfoliative width of the footing decrease as the horizontal spring constant decreases, as shown in Fig. 29 and Fig. 30.

These results show that, as the yield displacement increases, the structure exhibits improved sliding and the vertical acceleration decreases; as energy absorption increases, the reaction forces of the springs decrease and the stress acting on the isolator decreases as well; and, consequently, the aseismicity of the pier tends to improve.

\section{(6) Effects of vertical input}

In this analysis, the friction coefficient is assumed to be 0.10 and 0.20 , and the constants of the isolator are used as shown in Table 4. As for the earthquake input, the Port Island EW Wave and the Port Island UD Wave are adopted.

Table 8 and Table 9 show the maximum normal stress at the isolator, exfoliative width of the footing, and the reaction force of the base springs. According to the comparison presented in these tables, it is clear that vertical input has little effect on aseismicity.

As an example, the results for the case where $\mu=$ 0.10 are presented in the following sections. Fig. 32 shows the response displacement. The horizontal displacement, especially the residual displacement, is affected by the vertical input as shown in Fig. 32 (a), but the rotation angle of the isolator exhibits barely any effect as shown in Fig. 32 (b). The sliding velocity is shown in Fig. 33. It is clear that there is hardly any effect on the sliding velocity.

Table 8 Normal stress of the isolator and footing's exfoliative width

\begin{tabular}{|l|r|r|r|r|}
\hline & \multicolumn{2}{|c|}{$\begin{array}{c}\text { Isolator's normal stress } \\
(\mathrm{kPa})\end{array}$} & \multicolumn{2}{c|}{$\begin{array}{c}\text { Footing's exfoliative } \\
\text { width }(\mathrm{mm})\end{array}$} \\
\hline$\mu$ & 0.10 & 0.20 & 0.10 & 0.20 \\
\hline EW 1) & 10085 & 18965 & 6.15 & 68.35 \\
\hline EW+UD (2) & 9767 & 20168 & 8.70 & 66.50 \\
\hline $1 /(2)$ & 1.033 & 0.940 & 0.707 & 1.028 \\
\hline
\end{tabular}

Table 9 Reaction force of the base springs

\begin{tabular}{|l|c|c|c|r|}
\hline & \multicolumn{2}{|c|}{$\begin{array}{c}\text { Horizontal reaction foce } \\
(\mathrm{kN})\end{array}$} & $\begin{array}{r}\text { Rotation reaction force } \\
(\mathrm{kNm})\end{array}$ \\
\hline$\mu$ & 0.10 & 0.20 & 0.10 & \multicolumn{1}{c|}{0.20} \\
\hline EW 1) & 12227 & 15703 & 144459 & 249489 \\
\hline EW+UD (2) & 12464 & 15525 & 142574 & 238173 \\
\hline $1 /(2)$ & 0.981 & 1.011 & 1.013 & 1.048 \\
\hline
\end{tabular}

Regarding the vertical acceleration of the bridge pier, the influence exerted by vertical input is large as shown in Fig. 34 (b); but Figs. 34 (a) and (c) show that there is hardly any effect on horizontal and angular acceleration. Furthermore, Fig. 35 shows the absorption energy by sliding; there is also barely any difference between the EW input and the EW+UD input.

As mentioned above, vertical input generally does not affect the aseismicity of this isolating structure.

\section{MODEL VIBRATION EXPERIMENTS}

\section{(1) Experiment outline}

In order to investigate the oscillation behavior and the aseismicity of this isolation system, a model vibration experiment is carried out. An experimental model (1/36 of proto-type) is made of a pier with a pile foundation and the weight of the superstructure portion supported by the pier concerned. Law of similitude of the model experiment here is the same as that of ordinary vibration model experiments in gravitational field. Regarding the ratios of prototype to model, that of displacement is 36 , that of acceleration is 1 , and that of time is 6 . The weight of the superstructure is given by steel plates; the substructure is made from mortar; and the pile foundation is modeled using a frame structure consisting of ten aluminium beams (arranged $4+2+4$ in the vibration direction) and a foundation raft. The beams have a rectangular section that is $10 \mathrm{~mm}$ wide in the vibration direction, $20 \mathrm{~mm}$ deep and $630 \mathrm{~mm}$ long. The rigidity of the frame structure is determined by both the ambient soil rigidity and the cast-in-place piles. To measure the vibration behavior, accelerometers are installed at the top of the steel plates in horizontal and vertical directions, as well as vertically on both edges of the footing, and horizontally at the center of the footing and the foundation raft. The displacement transducers are set up horizontally in the steel plates, the footing and the foundation raft to measure the displacement of the superstructure and the sliding displacement of the isolator. Moreover, strain gauges are attached on top of the aluminum beams to measure the axial and bending strains. The experimental model, the measurement apparatus arrangement and the general outline of the experiment are shown in Fig. 36.

It is understood that there is a large aseismatic effect when using a layer of sand as the isolating material ${ }^{11), 12)}$. The use of PTFE (Teflon sheet) is only referred to briefly as an isolator material in this paper. The structure factors of test models are shown in Table 10. 


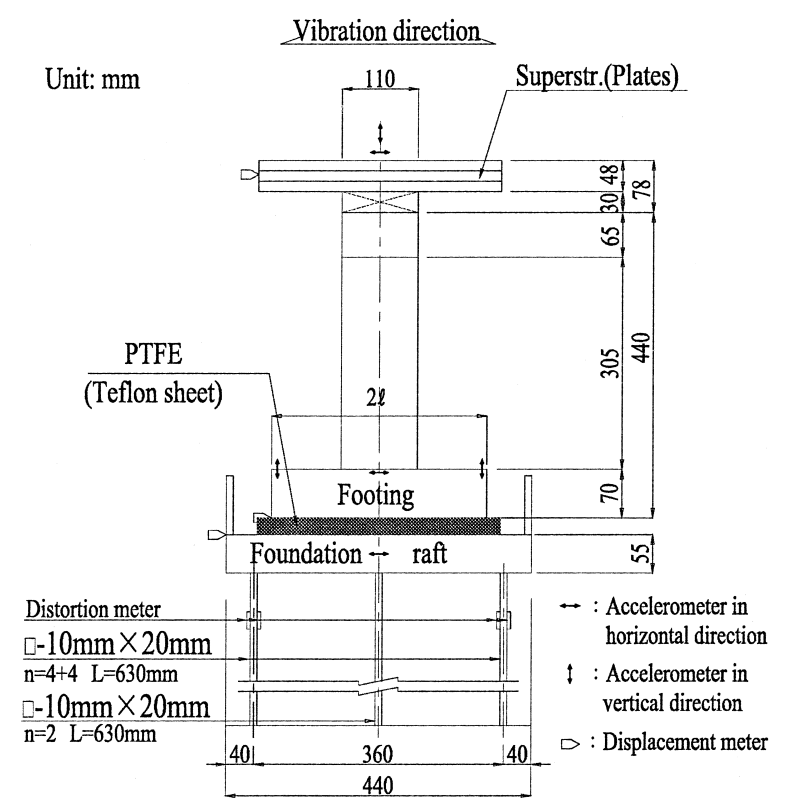

(1) Experimental model and measurementapparatus arrangement

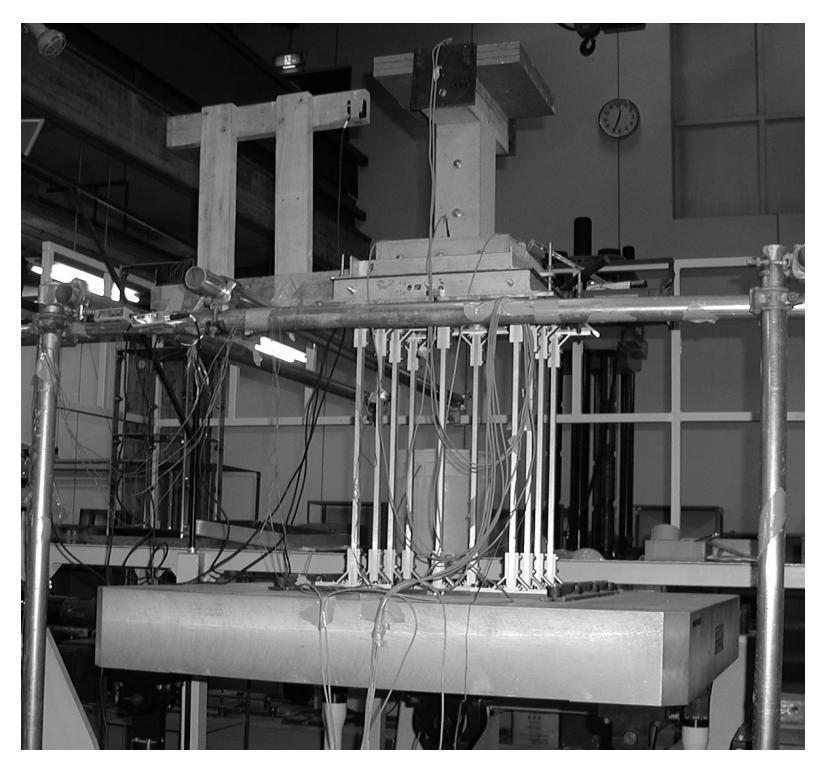

(2) General view of the experiment

Fig. 36 Outline of the experiment

Table10 Structure factors of the experimental model

\begin{tabular}{|c|l|r|}
\hline \multirow{4}{*}{ Mass $(\mathrm{kg})$} & Superstructure $m_{1}{ }^{\prime}$ & 49.5 \\
\cline { 2 - 3 } & Substructure $m_{1}{ }^{\prime}$ & 32.8 \\
\cline { 2 - 3 } & Subtotal $m_{1}=m_{1}{ }^{\prime}+m_{1}{ }^{\prime}$ & 82.3 \\
\cline { 2 - 3 } & Foundation raft $m_{2}$ & 39.9 \\
\cline { 2 - 3 } $\begin{array}{c}\text { Gravity center } \\
(\mathrm{mm})\end{array}$ & Total $m_{1}=m_{1}+m_{2}$ & 122.3 \\
\cline { 2 - 3 } & Superstructrue $h_{1}{ }^{\prime}$ & 494 \\
\cline { 2 - 3 } & Substructure $h_{1}{ }^{\prime}$ & 155 \\
\cline { 2 - 3 } & Above isolator $h_{1}$ & 358 \\
\cline { 2 - 3 } $\begin{array}{r}\text { Width of footing in the vibration } \\
\text { direction 2 } \ell(\mathrm{mm})\end{array}$ \\
\hline \multicolumn{2}{|c|}{ Ratio of $2 \ell$ to $h_{1}$} & 310 \\
\hline
\end{tabular}

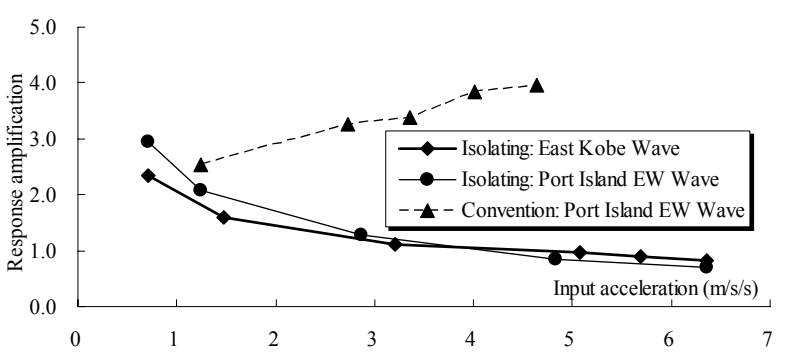

(1) Response amplification of the horizontal acceleration
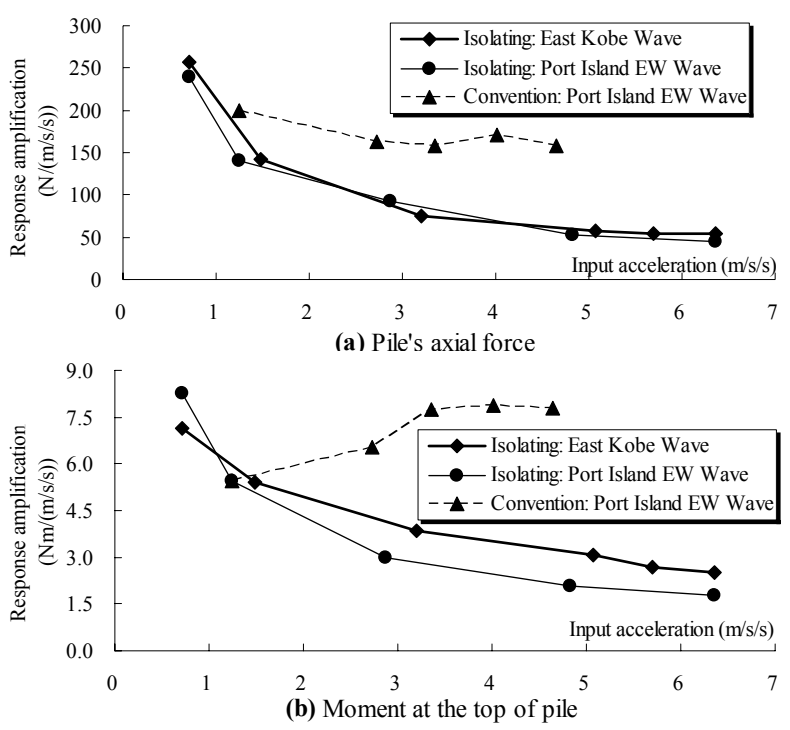

(2) Response amplification of the pile section force

Fig. 37 Response amplifications

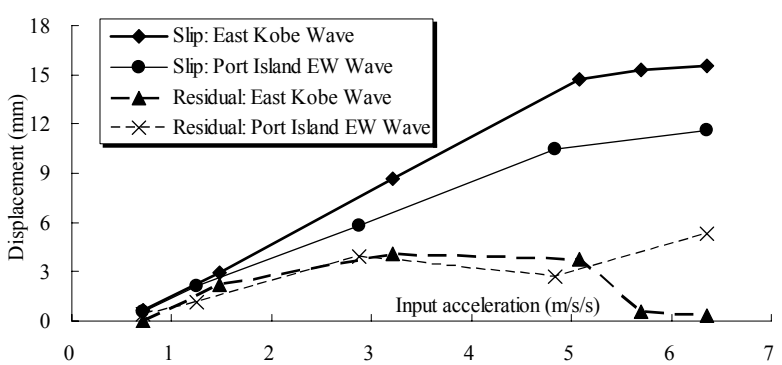

Fig. 38 Slip and residual displacements

The earthquake inputs for the experiments are the East Kobe Wave and the Port Island EW Wave, and the maximum amplitude of the input wave acceleration gradually increases from about $0.80 \mathrm{~m} / \mathrm{s}^{2}$ to about $6.50 \mathrm{~m} / \mathrm{s}^{2}$.

\section{(2) Experimental results and consideration}

Fig. 37 shows the response amplifications of the superstructure's horizontal acceleration and the section forces of the piles. When the input amplitude is small, the response acceleration does not differ much between the conventional structure and the isolating structure; but, as the input amplitude increases, the response amplification of the conventional structure also increases; while the response amplification of the isolating structure decreases. At the point of 
maximum input of the conventional structure, the response acceleration of the isolating structure is less than $1 / 4$ that of the conventional structure as shown in Fig. 37 (1). The section forces of the piles present the same tendency for superstructure acceleration, as shown in Fig. 37 (2). At the point of maximum input of the conventional structure, the axial force of the isolating structure is about $1 / 3$ that of the conventional structure, and the moment of the pile top is about $1 / 3$ as well. It is thought that with the increase of input amplitude, the isolating structure begins to slide and rock, emanating vibration energy. The slip displacements and residual displacements of the superstructure are shown in Fig. 38. The slip displacements increase as the input amplitude increases; the residual displacements increase as well when the input amplitude is less than about $3.0 \mathrm{~m} / \mathrm{s}^{2}$; but, when the input amplitude exceeds $3.0 \mathrm{~m} / \mathrm{s}^{2}$, the residual displacements hardly increase at all.

As one example, the response time histories by the Port Island EW Wave with maximum input amplitude are shown in Fig. 39 and Fig. 40. Fig. 39 (1) shows that almost all the relative displacements between the superstructure and the foundation raft are caused by the sliding of the isolator, i.e. the oscillation depends on sliding. In Fig. 39 (2), when the peak magnitude of the input wave is $6.36 \mathrm{~m} / \mathrm{s}^{2}$, the horizontal response acceleration at the superstructure with the isolating device is only $4.40 \mathrm{~m} / \mathrm{s}^{2}$; meanwhile, the response of the conventional structure rises to 18.42 $\mathrm{m} / \mathrm{s}^{2}$ where the peak magnitude of the input wave is $4.65 \mathrm{~m} / \mathrm{s}^{2}$. The maximum for the vertical response acceleration of the superstructure with the isolating structure is $1.34 \mathrm{~m} / \mathrm{s}^{2}$. Fig. 40 shows that regarding the bending moment of the pile top, the maximum response of the isolating structure is $11.4 \mathrm{Nm}$ when the peak magnitude of the input wave is $6.36 \mathrm{~m} / \mathrm{s}^{2}$. On the other hand, the bending moment for the conventional structure intensifies to $36.2 \mathrm{Nm}$ when the peak magnitude of the input wave is $4.65 \mathrm{~m} / \mathrm{s}^{2}$. These results show that the horizontal acceleration at the superstructure and the bending moments at the pile section decrease when the isolating system is adopted.

Fig. 41 shows the results of a Fourier spectrum analysis of the horizontal acceleration at the superstructure of the conventional structure and the isolating structure. It is shown that the resonate point of the conventional structure is about $4.9 \mathrm{~Hz}$; meanwhile no clear resonate point appears for the isolating structure. The dominant resonate point of the oscillation mode for the conventional structure disappears when the isolating system is adopted.

The sliding force-displacement hysteretic curve of the isolator is shown in Fig. 42. As with Fig. 9 (5) (a), the inclination is almost 90 degrees. The sliding

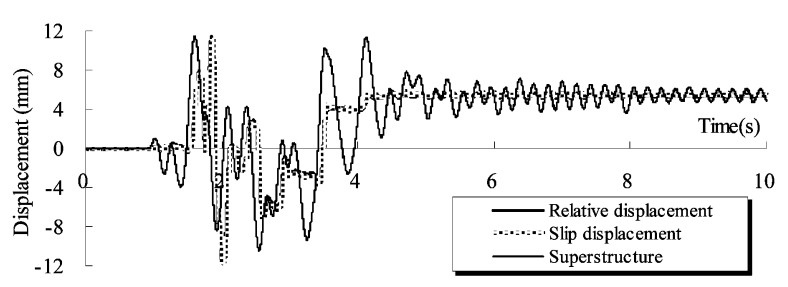

(1) Horizontal displacement

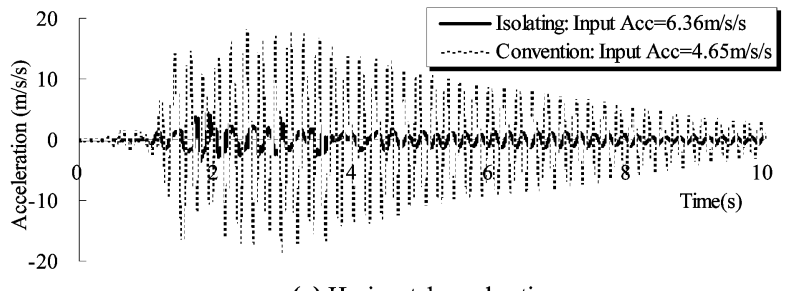

(a) Horizontal acceleration

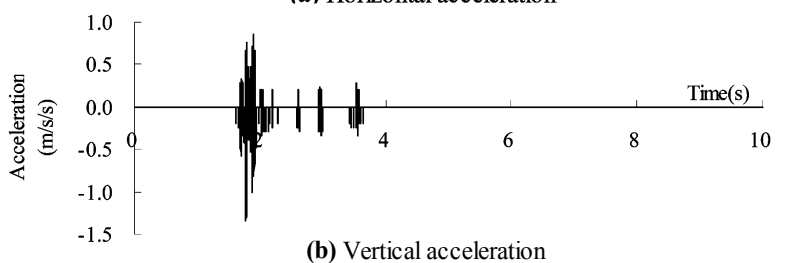

(b) Vertical acceleration

(2) Acceleration of the superstructure

Fig. 39 Displacement and acceleration

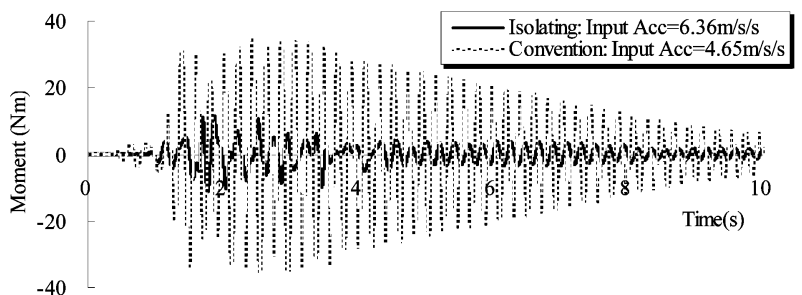

Fig. 40 Bending moment of the pile's top

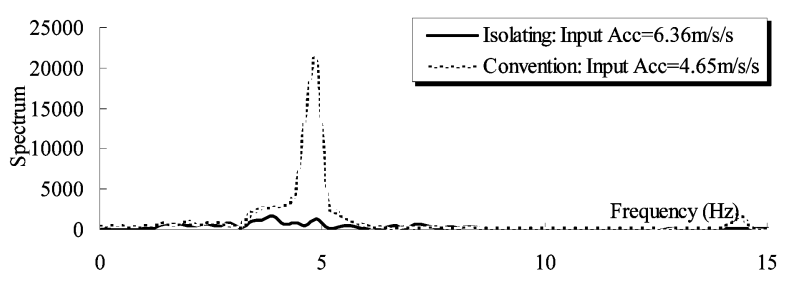

Fig. 41 Fourier spectrum of the horizontal acceleration at the superstructure

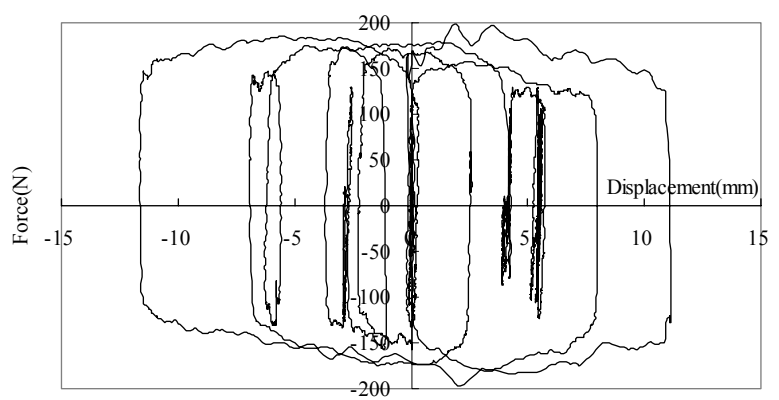

Fig. 42 Sliding force $\sim$ displacement

force is calculated by the following equation:

$$
F=m_{1} a_{c}=m_{1}\left\{a_{s}-\left(a_{s}-a_{f}\right) h_{s c} / h_{s f}\right\}
$$

where, $m_{1}$ is the mass above the isolator, $a_{c}$ is the horizontal acceleration at the gravity center above the isolator, $a_{s}$ is the horizontal acceleration at the su- 
perstructure, $a_{f}$ is the horizontal acceleration at the footing, and $h_{s c}, h_{s f}$ are the distances between the superstructure and the gravity center, and the footing, respectively.

The accumulation of energy absorption is shown in Fig. 43. It is clear that almost all energy absorption is calculated by the sliding. The model experiment results show that the isolating structure has a considerable effect on earthquake energy absorption. Moreover, as a sliding material, PTFE can provide a steady sliding force-displacement hysteretic curve.

\section{(3) Simulation of the experimental results}

The test results are simulated by dynamic response analyses. The experimental model is modeled to the calculation model as shown in Fig. 44. The isolator is modeled using a joint spring element. The isolator constants are presented in Table 11.

The friction coefficient is assumed to be 0.11 . The yield displacement is assumed to be $0.055 \mathrm{~mm}$, in conformity with the oscillation mode of the test model measured by the free vibration test. In addition, because the model is built to $1 / 36$ scale, the yield displacement of the proto-type would be about $2.0 \mathrm{~mm}$. The damping ratio of the aluminium beams in the simulation is determined by the results of the free vibration test conducted on the test model to be $3.0 \%$. The Port Island EW Wave with a peak magnitude of $6.36 \mathrm{~m} / \mathrm{s}^{2}$ is used as the input acceleration wave.

The comparison results of the simulation and the experiment are shown in Fig. 45 Fig. 48. Fig. 45 (1) shows that, as for the maximum horizontal response displacement of the superstructure, the experimental value is $11.4 \mathrm{~mm}$ and the analytical value is $14.3 \mathrm{~mm}$. The maximum slip displacement by the experiment is $11.7 \mathrm{~mm}$ and that by the analysis is $14.9 \mathrm{~mm}$. As for the residual displacement, the experimental value is $5.5 \mathrm{~mm}$, and the analytical value is $7.0 \mathrm{~mm}$. As for the displacements, the results of the analysis are roughly in agreement with the experimental results for both the maximum value and the wave form. As for the maximum acceleration, the horizontal responses by the experiment and the analysis are $4.40 \mathrm{~m} / \mathrm{s}^{2}$ and $3.70 \mathrm{~m} / \mathrm{s}^{2}$, respectively, and the vertical responses are $1.34 \mathrm{~m} / \mathrm{s}^{2}$ and $2.66 \mathrm{~m} / \mathrm{s}^{2}$ respectively as shown in Fig. 45 (2). As to the accelerations, the analytical results are on the whole in agreement with the experimental results. For the maximum bending moment at the pile top, the experimental value is $9.1 \mathrm{Nm}$ and the analytical

Table 11 Constants of the isolator

\begin{tabular}{|r|r|r|r|}
\hline$k_{H}\left(\mathrm{kN} / \mathrm{m}^{3}\right)$ & $k_{H 2}\left(\mathrm{kN} / \mathrm{m}^{3}\right)$ & $k_{V}\left(\mathrm{kN} / \mathrm{m}^{3}\right)$ & Damping ratio \\
\hline $1.474 \times 10^{4}$ & 1.474 & $4.422 \times 10^{4}$ & $1.00 \%$ \\
\hline
\end{tabular}

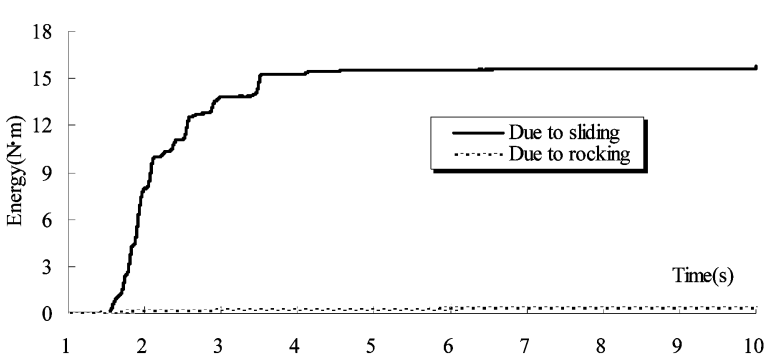

Fig. 43 History of the accumulation of energy absorption

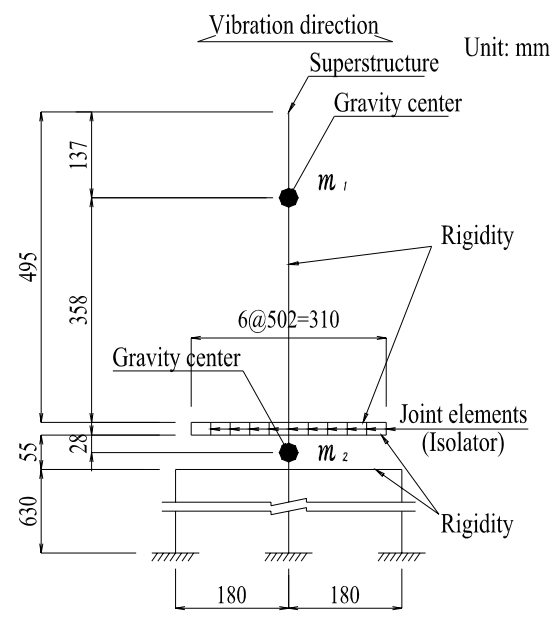

Fig. 44 Calculation model

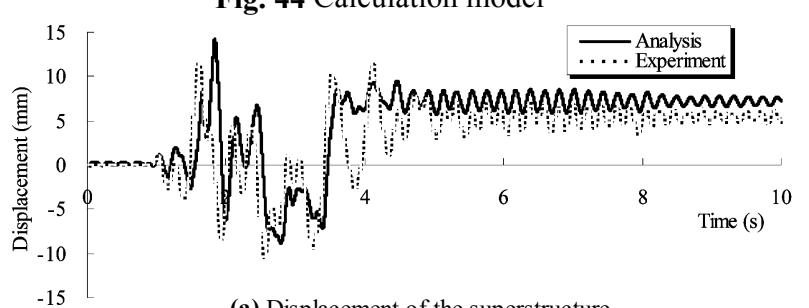

(a) Displacement of the superstructure

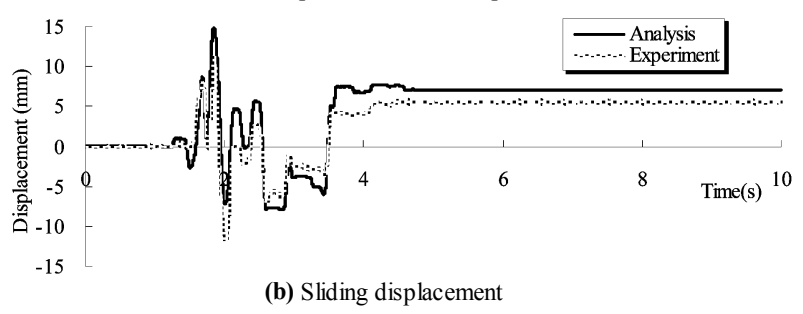

(1) Horizontal displacement

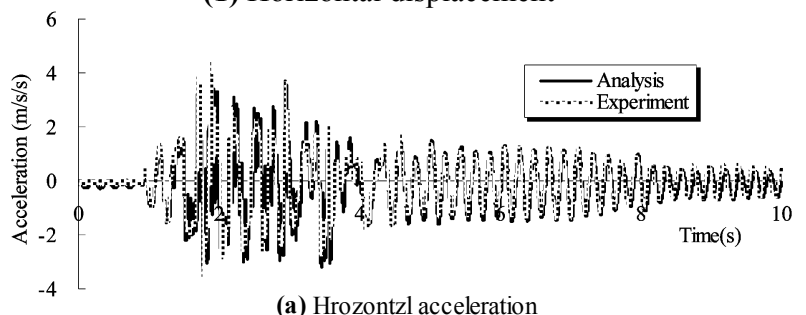

(a) Hrozontzl acceleration

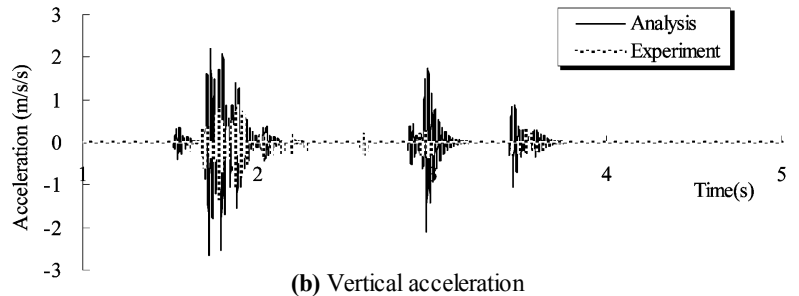

(2) Acceleration of the superstructure

Fig. 45 Displacement and acceleration 


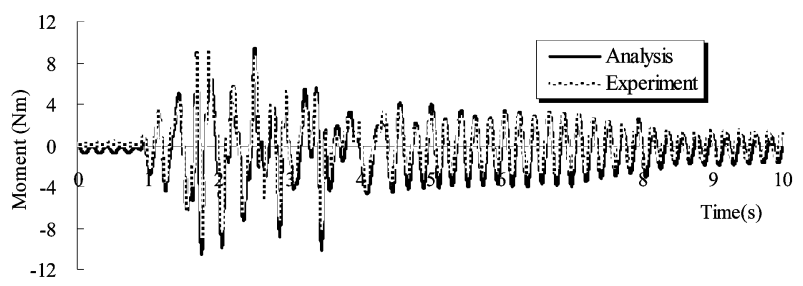

Fig. 46 Bending moment of the pile's top

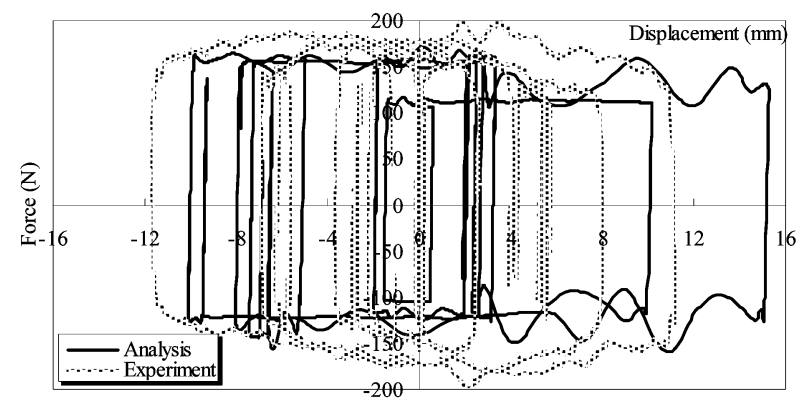

Fig. 47 Sliding force $\sim$ displacement

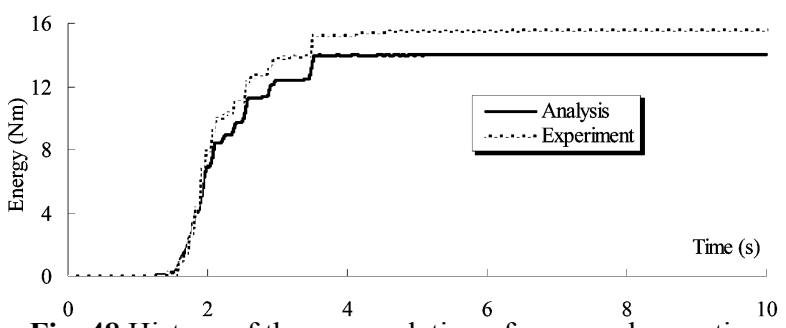

Fig. 48 History of the accumulation of energy absorpution

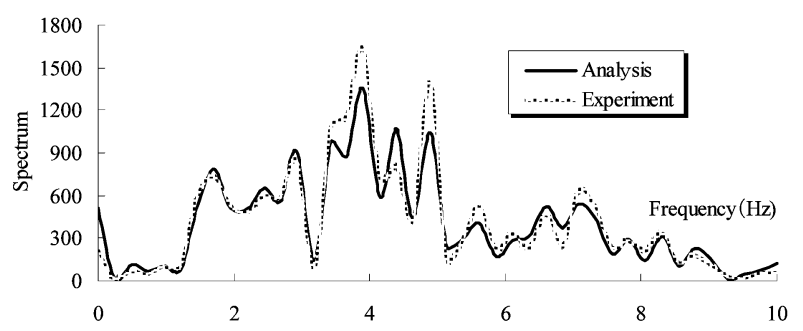

Fig. 49 Fourier spectrum of the horizontal acceleration at the superstructure

value is $10.5 \mathrm{Nm}$, as shown in Fig. 46. Waveforms and peak values obtained by analysis are almost in conformity with the experimental values. Fig. 47 shows the sliding force-displacement hysteretic curve. Hysteretic pattern for both the experiment and the analysis show much likeness. Fig. $\mathbf{4 8}$ shows the accumulation of energy absorption due to sliding. The accumulation value of the experiment is slightly greater than that of the analysis. Fig. 49 shows the Fourier spectrum of horizontal acceleration at the superstructure. According to Fig. 49, it is clear that the oscillation behavior of the model is reproduced exactly by analysis.

It is understood that the experimental results can be explained by dynamic analysis, thus the validity of the analytical model in this study is confirmed by these comparisons.

\section{CONCLUSIONS}

This paper investigated an isolating system that separates the substructure from the fundamental structure of a bridge pier. For a single bridge pier with this isolating system, the governing equations of motion are newly derived. The governing equations have geometrical and material nonlinear properties. By dynamic analysis and model vibration tests, the oscillation behavior of this isolating system is investigated. The conclusions obtained from the results are as follows:

1) The adopted isolating system in this study has excellent aseismicity, the responses of the horizontal acceleration and the reaction forces of the base springs decrease significantly whenever the oscillation mode is mainly a sliding one or mainly a rocking one.

2) The friction coefficient greatly affects the oscillation mode. Where $\mu<\ell / 3 h_{1}$, the oscillation will be mainly a sliding one. Where $\mu>2 \ell / 3 h_{1}$, the oscillation is mainly a rocking one. Moreover, the residual displacement has a tendency to increase as the friction coefficient increases in a mainly sliding oscillation.

3) For the mainly sliding oscillation, with an increase of $\ell / 3 h_{1}$, the sliding mode is more distinguished and the vertical acceleration decreases. The stress acting on the isolator also decreases.

4) As the yield displacement of the isolating materials increases, the structure slides easily; the vertical acceleration decreases; while the energy absorption increases, the reaction forces of base springs decrease; and the stresses acting on the isolator also decrease.

5) Where the input is both vertical and horizontal, the influence on structural aseismicity about the vertical input is small compared to where the input is only horizontal.

6) As a sliding material with a small friction coefficient, PTFE can provide a steady sliding force-displacement hysteretic curve.

7) The experimental results can be explained by the dynamic analysis of two rigid objects connected with springs at an interface. The validity of the analytical model considering both geometrical and material nonlinear properties in this study is confirmed.

In addition, as to the mainly sliding case, the residual displacement is effected by the characteristics of the earthquake wave, the friction coefficient and the aspect ratio of the structure above the isolator etc; it is thought that these influences ought to be study more detail. 
ACKNOWLEDGMENT: The authors would like to express their thanks to Mr. T. Watanabe and Mr. T. Kondou, master course students who assisted in the experiment and offered fruitful observations. This study was also conducted in cooperation with Penta Ocean Ltd. and Oriental Consultants Ltd.

\section{REFERENCES}

1) Japan Road Association: Specifications for Highway Bridges, part V, seismic design, 2002.

2) Kawashima, K., Hosoiri, K.: Effect of nonlinear rocking response of direct foundations on the hysteretic behavior of bridges, Journal of Structural Mechanics and Earthquake Engineering, JSCE, No. 703/I-59, pp. 97-111, 2002 (in Japanese).

3) Housner, G. W.: The behavior of inverted pendulum structures during earthquakes, Bulletin of the Seismic Society of America, Vol. 53, pp. 403-417, 1963.

4) Kawashima, K.: Seismic Design of the Rion-Antirion Bridge, Bridge and Foundation Engineering, pp. 33-36, 2001-3 (in Japanese).

5) Tachibana,Y., Tanaka,T.: Seismic isolated foundation of long span bridge, Proceedings of the JSCE Earthquake Engineering Symposium, Vol. 23, pp. 529-532, 1995 (in Japanese).
6) Ishiyama, Y.: Motions of rigid bodies and criteria for overturning by earthquake excitations, Earthquake Engineering and Structure Dynamics, Vol. 10, pp. 635-650, 1982.

7) Kimura, J., Iida, K.: Study on rocking in rectangular columns, Zishin, Vol. 6, No. 4. pp. 125-149, 1934 (in Japanese).

8) Shenton, H. W. III, Jones, N. P.: Base excitation of rigid bodies. I: Formulation, J. Engrg. Mech., ASCE, Vol. 117, No.10,pp. 2286-2306, 1991.

9) Mostaghel, N., Hejazi, M., Tanbakuchi, J.: Response of sliding structures to harmonic support motion, Earthquake Engineering and Structure Dynamics, Vol. 11, pp. 355-366, 1983.

10) Otsuka,H.,Unjoh,S.: The sliding vibration behavior of spread foundation during earthquake, JSCE Journal of Earthquake Engineering, Vol. 23, 1995 (in Japanese).

11) An, T., Kiyomiya, O., Watanabe, T., Kondou, T.: Model vibration tests on bridge pier with isolating foundation, JSCE Journal of Earthquake Engineering, Vol. 27, 2003 (in Japanese).

12) An, T., Kiyomiya, O., Watanabe, T., Kondou, T.: Model vibration tests on bridge pier with isolating foundation, Proceedings of Annual Conference of the JSCE, Vol. 58, pp. 61-62, 2003 (in Japanese).

(Received April 18, 2005) 